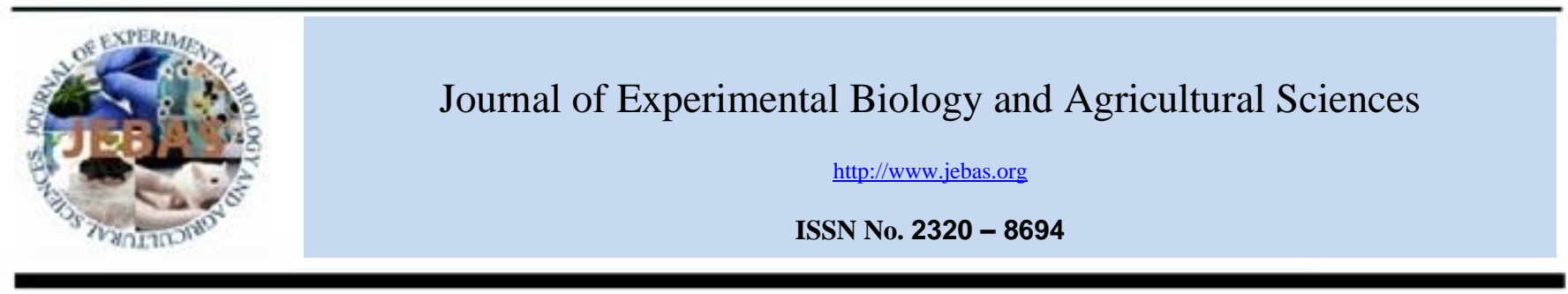

\title{
PREVALENCE, DIAGNOSIS, MANAGEMENT AND CONTROL OF IMPORTANT DISEASES OF RUMINANTS WITH SPECIAL REFERENCE TO INDIAN SCENARIO
}

\author{
Mani Saminathan ${ }^{1}$, Rajneesh Rana, ${ }^{2, *}$, Muthannan Andavar Ramakrishnan ${ }^{3}$, Kumaragurubaran \\ Karthik $^{2}$, Yashpal Singh Malik ${ }^{4}$ and Kuldeep Dhama ${ }^{1}$
}

\begin{abstract}
${ }^{1}$ Division of Pathology, ICAR-Indian Veterinary Research Institute, Izatnagar, Bareilly, India
${ }^{2}$ Division of Bacteriology and Mycology, ICAR-Indian Veterinary Research Institute, Izatnagar, Bareilly, India

${ }^{3}$ Division of Virology, ICAR-Indian Veterinary Research Institute, Mukteswar Campus, Uttarakhand - 263 138, India

${ }^{4}$ Division of Biological Standardization, ICAR-Indian Veterinary Research Institute, Izatnagar, Bareilly, India
\end{abstract}

Received - May 05, 2016; Revision - May 09, 2016; Accepted - May 21, 2016

Available Online - May 25, 2016

DOI: http://dx.doi.org/10.18006/2016.4(3S).338.367

KEYWORDS
Ruminant Diseases
Prevalence
Diagnosis
Prevention
Management
Control
India

\begin{abstract}
India possess huge livestock population, which is endangered by different endemic infectious diseases (bacterial, viral, protozoan and parasitic), which collectively causes significant economic losses to the landless poor farming community. Infectious diseases impose economic losses by causing morbidity, mortality, decreased production (milk, meat, wool etc.), decreased feed conversion ratio which results in reduced weight gain, decreased draught power and fertility. Furthermore, economic burden is also due to the cost of treatment, abortion, consequences on internal livestock movement, germplasm and international trade. In addition, some of the diseases are zoonotic and inflicts considerable impact on public health. Uncertain agrarian climate, unpredictable weather, drought, floods, migration of livestock, scarcity of fodders, and unhygienic zoo-sanitary and healthcare practices together resulted in endemicity of diseases ultimately leads to more incidence and prevalence of livestock and poultry diseases throughout the year. Synchronized monitoring and surveillance of disease throughout the country is a fundamental requirement for sustainable livestock production. With fairly developed telecommunication in India, following technologies like interactive voice response system, SMS through mobile/cell phones and toll-free landline phones (voice mail) are required for enhancing the effectiveness and efficiency of
\end{abstract}

\section{* Corresponding author \\ E-mail: rajneeshrana01@yahoo.com (Rajneesh Rana)}

Peer review under responsibility of Journal of Experimental Biology and Agricultural Sciences.

Production and Hosting by Horizon Publisher India [HPI] (http://www.horizonpublisherindia.in/).

All rights reserved.
All the article published by Journal of Experimental Biology and Agricultural Sciences is licensed under a Creative Commons Attribution-NonCommercial 4.0 International License Based on a work at www.jebas.org.

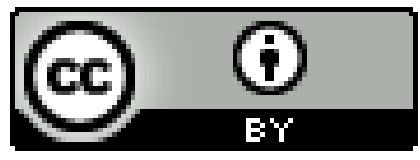


disease monitoring and surveillance. Multidisciplinary approaches at international, national and local levels are required for management, control and eradication of endemic and transboundary diseases of livestock. Improved monitoring and/or surveillance, rapid and confirmatory diagnosis, and networking of diseases are required to go forward in the path of eradication. Vaccination is the main strategy for control and eradication of many diseases. Good management practices consisting of stringent biosecurity measures, strick sanitation and hygiene practices in the farm, isolation and quarantine of diseased animals, and trade restrictions are necessary for successful operation of control programmes. This review highlights prevalence, pathogenesis, diagnosis, and prevention and control measures for important diseases of ruminants with special reference to India.

\section{Introduction}

India possesses rapid growing animal husbandry sector and moving towards to attain self-sufficiency in the production of livestock products (Dhama et al., 2014a). The animal husbandry department is a major contributor to the Indian economy and overall contribution is $28-32 \%$ in agricultural GDP and 4 to $6 \%$ of the national GDP. It also contributes 8 $10 \%$ of the country's labour power (Hemadri \& Hiremath, 2011). India possess largest livestock population in the world with 528 million of domesticated animals; first place in the world in buffalo population (105.3 million), second in cattle (199 million) and goat (140.5 million) population, and third in sheep (71.5 million) population (Hemadri \& Hiremath, 2011; Biswal et al., 2012; Dhama et al., 2014a; Chand et al., 2015). Livestock population in India is threatened by disease outbreaks, droughts, floods and other climatic anomalies.

There are several diseases affecting livestock that causes serious effect on the production of animals, human health, trade of livestock and animal products, as a result the overall economic development will be affected (Gibbs, 1981; Depa et al., 2012; Dhama et al., 2014a). Improved quality and quantity of livestock products is necessary, in order to compete in the international market, which intern needs disease free animal health status (Bhanuprakash et al., 2011; Awase et al., 2013; Bayry, 2013; Chand et al., 2015). In recent times, emerging and re-emerging diseases of livestock, poultry and humans have tremendously increased. Many of the diseases like brucellosis, tuberculosis, glanders, corona, influenza, Nipah and Hendra viral diseases are of zoonotic significance (Chakraborty et al., 2014; Dhama et al., 2014a; Kumar et al., 2015a).

Beside that several other viral diseases of animals in India such as foot and mouth disease (FMD), bluetongue (BT), peste des petits ruminants (PPR), sheeppox, goatpox, camelpox, infectious bovine rhinotracheitis (IBR), malignant catarrhal fever (MCF) and bacterial disease like haemorrhagic septicaemia (HS), black quarter (BQ), anthrax and brucellosis were endemic and has potential of crossing continental boundaries (Arya \& Bhatia, 1992; Benkirane \& De Alwis, 2002; Bhanuprakash et al., 2011; Biswal et al., 2012; Saminathan et al., 2013; Bayry, 2013; Chand et al., 2015; Kumar et al., 2015a). Emergence of new serotypes in various pathogens creates additional risk and warning to the livestock and human population. Higher occurrences of emerging and reemerging diseases might be due to various factors like crowded livestock and human population, deforestation, lack of public awareness and increased contact between livestock and humans with wild animals and birds (Depa et al., 2012; Chakraborty et al., 2014). The global expansion of cultivating land, population growth, intensive industrialization, climate changes, movement of vectors, illegal and unregulated trade, hiding/reduced reporting of the disease outbreaks are other reasons for the emergence and spreading of the disease (Gibbs, 1981; Dhama et al., 2014a,). Two-thirds of the global population including human and livestock are living in the developing countries and majority of the diseases were emerged from developing countries. International and national collaboration along with sincere scientific implementations and political decisions are necessary to tackle such emerging infectious diseases (Bhanuprakash et al., 2011; Hemadri \& Hiremath, 2011; Biswal et al., 2012).

An effective management for emerging and re-emerging diseases needs multidisciplinary activities like surveillance, rapid reporting, collection and transport of clinical materials for diagnosis of the etiological agents, strengthening of basic research, epidemiological modelling and prediction, forecasting model development, development of novel vaccine candidates and suitable adjuvants etc. (Biswal et al., 2012; Depa et al., 2012; Chand et al., 2015). The present review discusses the prevalence, pathogenesis, diagnosis and prevention and control measures for important diseases of ruminants with special reference to India.

\section{Viral diseases of ruminants}

\subsection{Foot and Mouth Disease (FMD)}

Foot and mouth disease (FMD) is endemic in India from 1864 onwards (Subramaniam et al., 2013). Animal population in India is threatened by FMD owing to unrestricted movements of animals, incomplete vaccinations, and inapparent infection in small ruminants which act as reservoirs. Direct loss of 20,000 crore/annum has been estimated due to the disease (Venkataramanan et al., 2006). FMD causes huge economic losses and decrease in milk yield causes $8 \%$ of total direct loss (Mathew \& Menon, 2008). The other economic losses were huge expenditure spent for FMD control programmes throughout the country by the government, increased cost for 
treatment, decreased productivity (meat, wool etc.) and draught power. The disease causes severe damage to the production and international trade. Because of its severity, the OIE and FAO declared it as "High Priority Disease". The body also appealed to different countries to make effective groups for its strategic control (FAO \& OIE, 2012). FMD affects wide variety of host including 529 million of livestock as well as captive and free-living wild even toed animals (Verma et al., 2008; Verma et al., 2012). Among 7 serotypes (O, A, C, Asia1, SAT-1, SAT-2 and SAT-3), only O, A, C, and Asia-1 were recorded in India. Since 1995, C serotype has not been reported from India and the globally the last outbreak was reported in Ethiopia during 2005 (Rweyemamu et al., 2008). About $70-80 \%$ of outbreaks are due to ' $\mathrm{O}$ ' followed by Asia 1 (3-10\%) and A (3-6.5\%) (Hemadri \& Hiremath, 2011; Biswal et al., 2012; Pattnaik et al., 2012). The FMD incidence is increased in India due to the execution of schemes for indigenous cattle genome improvement by cross-breeding of local cattle breeds with exotic cattle.

FMD incidences were more during pre-monsoon and winter season; however incidence of FMD were reported regularly all the months of year. The probable reason for its continuous persistence is due to uncontrolled animal movements throughout the country. Besides that because of the weak financial status of some of the livestock owners; their herd remains unvaccinated which posses' additional threat to the surrounding vaccinated herds. It has been reported that among 10 genotypes of serotype A, only 2 called as VI and VII were circulating in India from past 20 years. In Asia 1 serotype, VIA and VIB genotypes were circulating in India (Verma et al., 2010; Hemadri \& Hiremath, 2011; Biswal et al., 2012; Pattnaik et al., 2012; Subramaniam et al., 2013). The control and eradication of FMD in India, progressive control pathway (PCP) was implemented (Rweyemamu et al., 2008). The FMD control programme (FMDCP) was executed in 54 districts from 8 states of India during $10^{\text {th }}$ five year plan (based on epidemiological data obtained from more than 35 years) covering the population of 30 million cattle and buffalos. In the control program implemented areas, there has been gradual build up of herd immunity and substantial fall in the disease incidence (Biswal et al., 2012; Depa et al., 2012; Pattnaik et al., 2012; Verma et al., 2012; Subramaniam et al., 2013).

\subsection{Peste des Petits Ruminants (PPR)}

Peste-des-petits-ruminants (PPR) is a highly contagious, acute and transboundary viral disease of goats and sheep caused by the genus Morbillivirus belonging to the family Paramyxoviridae. Clinically, the disease is manifested as conjunctivitis, high fever, oculonasal discharge, necrotizing and erosive stomatitis, enteritis and bronchopneumonia followed by either mortality or recovery from the disease (Taylor, 1984). Currently, as South Asia is more focused for PPR, it percolates serious losses to the countries like Afghanistan, Pakistan, Nepal, Bangladesh and India. The disease was first observed in Tamil Nadu in 1987 (Shaila et al., 1989). On the genomic basis the virus is grouped into four lineages i.e. I, II, III, and IV out of which lineage IV is common in Asia (Balamurugan et al., 2012). In India, till date, only lineage IV viruses have been reported. In North-eastern regions the seroprevalence rate of PPR in goats was $13.8 \%$ in Assam (Begum et al., 2016) and $2.11 \%$ in Tripura. The PPRV goat strain isolated during 2013 outbreak in Tripura region of India shared 99.2 to $99.6 \%$ nucleotide identities with the Bangladeshi strains (Muthuchelvan et al., 2014).

The disease outbreak is most commonly observed in the months of April to October followed by winters. Goats were more susceptible to PPR and manifest severe clinical form of disease than sheep. A report from central India showed occurrence of dual infection of PPR and Goatpox in indigenous goats (Malik et al., 2011a). Several PPR outbreaks were encountered and the disease is enzootic in most of the southern states of India like Karnataka, Andhra Pradesh and Tamil $\mathrm{Nadu}$; western states of India like Maharashtra; eastern states of India like West Bengal and Orissa; northern states of India like Rajasthan and Himachal Pradesh; central states of India like Madhya Pradesh (Dhar et al., 2002; Balamurugan et al., 2012; Singh et al., 2013; Muthuchelvan et al., 2015). The expected yearly losses due to this disease may reach up to 1800 million rupees. In northern region of India, outbreaks were most frequent in goats whereas in southern regions of India, the outbreaks were most frequent in sheep (Balamurugan et al., 2012; Balamurugan et al., 2014). The economic losses per animal in sheep and goats ranges between Rs. 523 to 945 (Thombare \& Sinha, 2009; Awase et al., 2013). The growth of goat industry is hampered by PPR owing to high morbidity (50-90\%) and mortality (50-85\%) rates. Kids more than 4 months and less than one year of age are more susceptible to PPR.

The occurrence of disease outbreaks was higher during March to June $(51.7 \%)$ when compared to remaining months (Thombare \& Sinha, 2009; Awase et al., 2013). The economic impact of PPR includes trade limitations; a hindrance to intensive livestock production development due to the impedance to the import of new breeds, which in turn cause scarcity of animal protein to humans. The control of PPR can be achieved by effective vaccination measures. Infected animals should be kept in quarantine for the period of one month. In the infected area, the movement of the animal should be restricted strictly. Practically, sanitary and control measures are difficult to follow in India due to vast nature and PPR endemicity. However, the effective measure for PPR control is mass vaccination using the effective vaccine, along with quarantine measures (Sen et al., 2010; Balamurugan et al., 2014; Muthuchelvan et al., 2015).

The control measures should contain the "bottom-up" approach such as from livestock owners to field veterinarians to policy makers (Singh, 2011). Further, increasing the production of PPR vaccine, enhancing the disease diagnostic facilities, strengthening the quality control units and improved infrastructure facilities for field workers is necessary for management and control of diseases. The NCP-PPR control 
scheme was implemented in 2010 and presently extended to all the states of the country (Balamurugan et al., 2014; Muthuchelvan et al., 2015).

\subsection{Bluetongue (BT)}

Bluetongue (BT) disease is now endemic in India and the first case of BT was reported from Maharashtra during 1964 (Sapre, 1964). Later on, the disease has been reported from several parts of the country based on virus isolation and/or detection of BTV-specific antibodies. BTV belongs to the genus Orbivirus of the family Reoviridae (Pringle, 1999). In serological survey, the presence of antibodies against BTV in Indian cattle, buffalos, goats, camels as well as in some wild ruminants has been observed. However, in cattle and buffalos, clinical form of BT has not been reported. The clinical signs vary from asymptomatic to fatal form which is determined by the BTV serotype, animal species, breed and age (Elbers et al., 2008). Recently, 27 BTV serotypes have been identified worldwide with the addition of 2 more new serotypes (Maan et al., 2011; Zientara et al., 2014). In India, 22 serotypes have been recognised on the basis of virus isolation and/or serology (Rao et al., 2016). Presently, 13 serotypes namely, BTV-1, 2, 3, 4, 6, $9,10,12,15,16,17,18,21$ and 23 were isolated from India especially from southern states (Maan et al., 2012; Minakshi et al., 2012; Rao et al., 2012; Chauhan et al., 2014). Genomic studies of these serotypes exhibit their variation with the standard reference strain (Rao et al., 2016). Culicoides spp. is the major vector for BTV. Among 1400 species were identified worldwide, minimum 39 species have been identified as vector for BT in India (Maheswari, 2012).

The analysis of outbreak data reveals that the intensity of disease outbreak was severe in Karnataka followed by Andhra Pradesh and Tamil Nadu (Hemadri \& Hiremath, 2011). During 2007-08, a severe outbreak of the disease was happened in India, afterwards only a mild clinical form of disease was observed (Hemadri \& Hiremath, 2011). Diagnosis of BT can be done by epidemiology, vector species, clinical signs, postmortem findings and molecular tests (Afshar, 1994). Confirmatory diagnosis can be done by virus isolation, detection of anti-BTV antibodies by serological methods and nucleic acid detection by RT-PCR. BTV can be isolated from chicken embryonated eggs and competitive ELISA (c-ELISA), virus neutralization test (VNT) and agar gel immunodiffusion (AGID) assay (Afshar et al., 1989; Pathak et al., 2008). By using RNA-PAGE, cell culture adapted Indian BTV with more than 10 segments have been reported (Ramakrishnan et al., 2005b). For successful control of BT in India, it is required to initiate vector and sentinel control measures and rapid disease diagnosis. The control measure for BT includes vaccination of animals with an inactivated BTV vaccine. Inactivated monovalent BT vaccines were developed using BEI (Ramakrishnan et al., 2006) and hydroxylamine inactivants (Ramakrishnan et al., 2005a). Recently, for control of BT in India, inactivated pentavalent vaccine consisting of BTV-1, 2, 10,16 and 23 was developed and commercialised (Reddy et al., 2010). Control of BT in India is a difficult task due to more susceptible host species and more BTV serotypes. However, control of BT can be achieved by protecting the susceptible animals from vector Culicoides but always this is also not possible. Control of vector can be done by using insecticides, but it is expensive and does not provide complete relief from the vector. In India, modified live vaccines (MLVs) are not preferred due to nomadic nature of animals' results in spreading of the disease. Therefore, for management and control of BT, inactivated multivalent vaccines are preferred (Chand et al., 2015).

\subsection{Sheeppox and goatpox}

Sheeppox virus (SPPV) and goatpox virus (GTPV) belongs to a member of the genus Capripoxvirus of the family Poxviridae. The sheeppox and goatpox diseases are notifiable to Office Internationale des Epizooties (OIE) due to its economic impact. In India, sheeppox and goatpox diseases are endemic, which are host specific and pose a serious economic loss to small ruminant husbandry (Bhanuprakash et al., 2006; Bhanuprakash et al., 2010; Bhanuprakash et al., 2011). Although, SPPV and GTPV are considered as host-specific they can cross the species barrier i.e. these viruses can infect both species (Santhamani et al., 2015). The outbreak of capripox was first reported in 1936 in India, and since then, frequent outbreaks have been reported throughout the country in almost all the states where sheep and goats are reared. The occurrence of the disease is usually observed throughout the year, however, most frequently seen during the rainy season (Garner et al., 2000). Mortality in young animals can exceed $50 \%$. A recent report revealed that the morbidity and mortality rates in the flock were $18.4 \%$ and $6.3 \%$, respectively (Hemadri \& Hiremath, 2011). Exotic and young animals are highly susceptible (Bhanuprakash et al., 2006). Certain predisposing factor for spreading out the disease is the presence of a virus on the wool of the recovered animal. The virus can be transmitted by aerosols from diseased animals, through direct contact with abraded skin and mucosa or indirectly by vectors through mechanical transmission (Kitching \& Mellor, 1986).

Direct losses due to mortality are low, however, morbidity and post-disease impacts on leather quality, wool, and meat productivity are more (Bhanuprakash et al., 2011). In the Maharashtra state of India, the economic losses due to capripox diseases are calculated as Rs. 105 million (US\$2.3 million) with an average morbidity and mortality of $63.5 \%$ and $49.5 \%$, respectively, and after 6 years the flock recovered from outbreak (Garner et al., 2000). By the estimation of these losses, the predicted total annual loss is Rs. 1250 million (US\$ 27.47 million) at the national level (Bhanot et al., 2009). The recovered animals from infection shall acquire lifelong immunity. In India, the slaughter policy and movement restrictions for disease control are difficult to follow due to various socio-economic factors. Therefore, an economical and sustainable approach for disease control is mass vaccination. Recently, P32-gene based PCR-RFLP and RPO30 and GPCR genes based sequencing analyses have been applied for the differentiation of Indian strains of SPPV and GTPV from field 
samples (Santhamani et al., 2013; Santhamani et al., 2014; Santhamani et al., 2015). Vaccination is practiced for many years mainly for sheep pox to decrease the endemic nature of the disease. Recently, live goat pox vaccine has been developed to reduce the disease incidence in goats (Bhanuprakash et al., 2011).

\subsection{Infectious Bovine Rhinotracheitis (IBR)}

Bovine herpesvirus 1 (BoHV-1) causes IBR, which consist of various clinical manifestations such as pustular vulvovaginitis, rhinotracheitis, balanoposthitis, infertility, abortion, mastitis, conjunctivitis and encephalitis in cattle. Mehrotra et al. (1976) first reported the disease in Uttar Pradesh, India and isolated the virus from calves affected with keratoconjunctivitis. Afterwards, the disease was reported from various parts of the country in India. The disease prevalence was more in crossbred and exotic breeds of cattle when compared to local breeds of cattle (Majumder et al., 2015a). IBR is usually transmitted by semen posing a serious risk to productivity and reproductive health (Huck et al., 1971). BoHV-1 is considered as most commonly found viral agent in the semen of bovines. Akin to other herpes viruses, BoHV-1 can cause latent infection and animals turn into reservoirs of the virus in the herd. Reactivation of virus from latent infection leads to shedding of the virus in the bull semen. BoHV-1 is maintained in the environment due its short cycle of infection, latent infection, resistance to environmental factors and reactivation during stress conditions (Muylkens et al., 2007; Nandi et al., 2009). BoHV-1 can cause considerable economic losses due to loss of body condition, abortion, milk yield, temporary failure of conception, loss of newborn calves, insufficient feed conversion, secondary bacterial pneumonia, cost of treatment and impact on national and international trade on germplasm and livestock (Gibbs, 1981; Majumder et al., 2015a). The mortality and morbidity rates differs among the breeds of cattle, which was lesser in milch breeds of cattle viz., 3\% mortality and $8 \%$ morbidity when compared to beef breeds and feed lot cattle, which shows higher mortality rates of 20$30 \%$ (Barenfus et al., 1963). The disease is not sex dependent as male and females are equally susceptible. Crossbred cattle are more susceptible than indigenous breed (Krishnamoorthy et al., 2015). Field virus infection or immunization using an avirulent strain of BoHV-1 virus resulted in development of latent infection. Sero-epidemiological data of BoHV-1 during 2009-10 in cattle and buffalo showed that the prevalence of disease was more in Tamilnadu (67\% prevalence rate) and Meghalaya state is being lowest in prevalence (Selvaraj et al., 2008). The significant levels of antibodies were detected in bovines having a history of reproductive problems and abortions. A study revealed high antibody prevalence of BoHV-1 in cattle $(50.9 \%)$ and buffaloes $(52.5 \%)$ from India (Renukaradhya et al., 1996).

The disease was reported in the yak with the overall prevalence of $40.8 \%$ (Rahman et al., 2007) and Mithun with overall prevalence of 19\% (Rajkhowa et al., 2004). In general in India, the prevalence rate of disease was $34 \%$ with differing prevalence rates in various parts of the nation includes $39 \%$ north-eastern, $37 \%$ northern, $25 \%$ central, $24 \%$ western and $17 \%$ eastern (Selvaraj et al., 2008; Bandyopadhyay et al., 2009a; Sarmah et al., 2015). In a recent report, 18\% seropositivity was reported in bovine serum samples in Tripura (Majumder et al., 2013a). The BoHV-1 can be detected by virus isolation, SNT, FAT in infected tissues, ELISA, and IPT. Virus isolation using cell culture has been commonly practised (Majumder et al., 2015a). There are very limited information is available on molecular characterization of Indian BoHV1. Very recently, $\mathrm{gB}, \mathrm{gC}$, and $\mathrm{gD}$ genes of Indian BoHV-1 isolate were characterized (Majumder et al., 2013b; Majumder et al., 2014, Majumder et al., 2015b). The increased percent prevalence of the disease in recent past indicates that the problem should be tackled by adopting strict sanitary measures, maintaining 2-3 weeks of quarantine period before introducing new stock to the herd and segregation of virus positive animals, vaccination and use of semen from disease free animals. In order to get rid of the virus from a herd, identification and slaughtering of infected animals are required due to the possibility of reactivation of virus from latent infection (Majumder et al., 2015a).

\subsection{Bovine viral diarrhoea (BVD)}

BVD is an endemic disease worldwide and causes considerable economic losses in cattle farming community. It is caused by bovine viral diarrhoea virus (BVDV) belongs to the genus Pestivirus of the family Flaviviridae. Based on the pathogenic behaviour in cultured cells, cytopathic and non-cytopathic biotypes of BVDV are identified. BVDV consists of two genotypes (type 1 and 2) and further subdivided into several genetic and antigenic variants. Both the genotypes cause acute and persistent infection. Although the main focus of the research in cattle, the virus can infect wider range of species including domestic and mountain goats (Nelson et al., 2015). The economic losses are due to prenatal infections, infertility, abortions, congenital anomalies in calves, more neonatal deaths and persistently infected (PI) calves, which die due to mucosal disease. The incidence of BVD is usually unnoticed due to 70 to $90 \%$ of infections were in subclinical form (Neibergs et al., 2011). The BVDV was isolated from clinical samples for the first time in India by Mishra et al. (2004). The incidence of BVD in cattle (Sood et al., 2007), sheep and goats (Mishra et al., 2009) and buffaloes (Mishra et al., 2008) in India has been reported using molecular confirmatory tools. Commonly circulating genotype in BVDV in Indian cattle is BVDV-1b (Mishra et al., 2004). BVDV-2 was identified from sheep and goats (Mishra et al., 2007; Mishra et al., 2008) and cattle (Behera et al., 2011) might be due to unrestricted migration and trading in ruminants.

Various serological studies have indicated the prevalence of BVDV antibodies in Indian cattle population (Nayak et al., 1982; Mukherjee et al., 1989; Sudharsana et al., 1999; Mishra et al., 2011). Post infected (PI) animals maintain the virus and play a major role in the spread of the virus among cattle population (Broderson, 2014). PI animals acquire the infection 
by in utero from non-cytopathic biotype of BVD virus during 45 to 125 gestation period results in immunotolerance (Hessman et al., 2012). PI animals excrete more viruses throughout their lifespan and act as a major source of virus spread between and within the farms. Because PI animals give negative results for a serological test for antibody detection, however, positive for BVD antigen, hence assays targeting viral antigens detection are ideal for their diagnosis in a herd.

\subsection{Picobirnaviruses}

The picobirnaviruses (PBV) have been identified as the emerging pathogens associated with enteric and respiratory infections in a number of mammalian and avian species. These are small structured viruses of nearly $35 \mathrm{~nm}$ with doublestranded bisegmented RNA genome. PBVs have been designated as genogroup I (GGI), genogroup II (GGII) and genogroup III (GGIII) based on sequence analysis of genome segment 2. In India, PBV was for the first time detected in bovine in West Bengal in 2009 (Ghosh et al., 2009) and subsequently from central India (Malik et al., 2011b). A PBV strain isolated from western Maharashtra from a buffalo calf showed huge genetic divergence (Malik et al., 2013a). Recently, we have identified and characterized a novel genogroup II picobirnavirus from a cattle calf (Malik et al., 2014), which is the first report of genogroup II detection from bovines. PBVs are detected together with other major enteric viruses such as rotavirus, astrovirus, coronavirus etc and are gaining importance these days. It is presumed that PBVs could be a potential threat for growing livestock industry due to leading gastroenteritis and associated economic issues.

\subsection{Bovine rotaviruses}

Rotavirus (RV) leads to severe gastroenteritis and has become a major health problem throughout the world. The RV infections enforce colossal economic losses mainly due to increased morbidity and mortality, treatment and poor growth performance of enteritis-affected animals. Though considerable research has been carried out on RV disease in humans in India, information is scanty on animal rotaviruses epidemiology. The RV associated clinical signs may vary from asymptomatic/subclinical to severe enteritis. The RV prevalence has been reported between $3.25 \%$ to $42 \%$ using serological and molecular methods during 1990-2001 (Mittal et al., 1991; Shah \& Jhala, 1992; Agarwal \& Singh, 1993; Gulati et al., 1995; Jindal et al., 2000; Khurana \& Pandey, 2001). The information generated through VP7 gene (G) and VP4 gene (P) genotyping of bovine RVs in various epidemiologic surveys confirms that (i) G3, G6, G8 and G10 constitute more commonly circulating $G$ genotypes and $P[11]$ as the $P$ genotype in the country; (ii) other G types, such as G15 with $\mathrm{P}[15]$ and $\mathrm{P}[21]$ types have been detected but are localized in some parts of the country; (iii) multiple $G$ and $P$ types can cocirculate within the same region (Malik et al., 2012) and can cross the inter-geographical boundaries of the states (Malik et al., 2013b). Concurrent infection with two or more pathogens is a common phenomenon and interactions among multiple pathogens often appear to generate a more severe or chronic outcome than is observed with the individual pathogen (Minakshi et al., 2009). Still very little is known about the specific interactions which occur in concurrent infections. Minakshi et al. (2009) reported the occurrence of dual infection of bovine group A rotavirus in a diarrhoeic calf in one of the northern state, Haryana, India. Malik et al. (2012) described the detection of G3 genotype in combination with G8 or G10 genotype. The control of the virus infection in both humans and animals is dependent on regular monitoring of newly emerging RVs and production of an effective vaccine to control rotavirus associated enteritis in young calves remains a challenge throughout the world.

\section{Bacterial diseases of ruminants}

3.1 Haemorrhagic septicaemia (HS)

Haemorrhagic septicaemia (HS) is the most significant bacterial contagious infection in cattle and buffaloes with proven endemicity in India (Shivachandra et al., 2011). The disease usually causes devastating and alarming problem in buffaloes and cattle. The course of disease becomes fatal when the aetiological agent enters in non-endemic areas of reared bovines. The disease was more severe in buffaloes when compared to cattle and young and young adult animals manifest more severe form of disease than older animals (Singh et al., 2014a). Moreover, the disease is widely reported from bison, African buffalo, camels, elephants, horses, donkeys as well as from yak. HS is an acute, fatal and septicemic disease of cattle and buffaloes caused by Pasteurella multocida (Rajeev et al., 2011; Shivachandra et al., 2011). P. multocida causes HS in cattle and buffaloes, and pneumonic pasteurellosis in sheep and goats. The most prevalent serotypes in India are B:2, A:1, A:1,3, A:3, A:4, $\mathrm{A}: 3,4,12, \mathrm{~F}: 3, \mathrm{D}: 1, \mathrm{D}: 3, \mathrm{~F}: 1, \mathrm{~F}: 4$ and F:4, 12. In an Indian molecular study of MLST conducted by Sarangi et al. (2016), 10 different sequence type were identified as ST 122, ST 50, ST 9, ST 229, ST 71, ST 277, ST 129, ST 280, ST 281 and ST 282. The B:2 serotype in India in pigs causes sporadic septicaemic disease. Apart from buffaloes, sporadic occurrence of the disease with $62 \%$ outbreak rates in goats, $102 \%$ in sheep and 5\% in pigs has been reported during 2007-2010. An estimated economic loss due to haemorrhagic septicaemia in India is Rs. 225 million per year (Singh et al., 2008a).

The economic loss due to HS has been calculated as Rs. 6816 per infected cattle and Rs. 10901 per infected buffalo. The total economic loss was Rs. 5255 crore estimated from throughout India. Among that, about $80.3 \%$ economic losses are due to direct effects of HS and $19.7 \%$ economic losses are due to indirect effects of HS. In HS, about $74.8 \%$ of the economic losses are due to affections in calves and $25.2 \%$ are due to loosses in adults (Singh et al., 2014a). In India, HS is the leading cause of mortality and second most commonly encountered disease during 1991 to 2010 reported by National Animal Diseases Referral Expert System (NADRES). According to NADRES report, approximately $97 \%$ of the HS 
outbreaks were occured in cattle and buffaloes (Gajendragad \& Uma, 2012). Epidemiological data of HS obtained during 1974 to 1986 revealed that it was the leading cause of mortality and second leading cause of morbidity than other enzootic diseases like RP, FMD, BQ and anthrax (Dutta et al., 1990).

During the last 4 decades, it has been found that HS caused 46 to $55 \%$ of mortality in bovines in India (Benkirane \& De Alwis, 2002). Diagnosis can be made on the basis of clinical signs and post-mortem findings and confirmatory diagnosis can be done by isolation and identification of etiological agent with appropriate staining (Rajeev et al., 2011). Vaccination is a major tool for the control of disease especially 2 to 3 months before the high-risk monsoon season. Although various HS vaccine types like oil adjuvant, alum-precipitated and various emulsion vaccines are commercially available, the search for suitable vaccines with long-lasting immunity and the good protective response is required. Good sanitary measures, early diagnosis, quarantine, isolation of infected animals, immediate antibiotics treatment, deep burial or incineration of carcasses and restriction of animal movements to disease-free areas are essential.

Awareness of the disease among farmers is required for effective disease reporting system (Benkirane \& De Alwis, 2002; Shivachandra et al., 2011). P. multocida has a zoonotic potential and infection to human spread through bites and scratches of the animals (especially dogs and cats) (Aski \& Tabatabaei, 2016). The infection may lead to ocular infection to fatality in humans (Corchia et al., 2015; Talley et al., 2016). Shivachandra et al. (2013) studied the genetic relatedness of ptfA gene among P. mutocida isolates of different species and observed that avian isolates are divergent from mammalian isolates (Shivachandra et al., 2013). Recombinant Omp87 protein of $P$. multocida serogroup B:2 strain P52 elicited increase in IgG response and provided a different level of protection against homologous and heterologous challenge (Kumar et al., 2013). Similarly, rVacJ protein elicited antigenspecific IgG response in immunized mice (Shivachandra et al., 2014b) and comparative amino acid sequence of different P. Mutocida isolates showed absolute homogeneity (Shivachandra et al., 2014a). In another study, it was demonstrated that recombinant transferrin binding protein $\mathrm{A}$ (rTbpA) elicited I antigen specific IgG response and provided a different level of protection in mice challenge (Shivachandra et al., 2015).

\subsection{Black quarter (BQ)}

BQ is a highly fatal and acute bacterial infection of cattle caused by Clostridium chauvoei affecting buffaloes, sheep, and goats. Young cattle and buffaloes with 6 to 24 months of age and good body condition are highly susceptible. C. chauvoei is normally present in the intestine of animals. In the soil, spores remain viable for many years and can act as a source of infection to animals. BQ is a soil-borne infection and outbreaks occur most commonly during the rainy season, in areas with moderate rainfall, where dry-crop cultivation is commonly practised. This disease is widely prevalent in cattle belonging to Karnataka, Andhra Pradesh, Tamil Nadu and Maharashtra states of India. One sporadic outbreak of the disease from eight HF crossbred cows has also been reported by Zahid et al. (2012) from Ludhiana, Punjab. During 2009-10, the highest outbreak of disease were reported from West Bengal with 95 outbreaks, in which 293 animals were affected and 122 animals were died and then in Maharashtra with 37 outbreaks, in which 128 animals were affected and 96 animals were died (Hemadri \& Hiremath, 2011). Combined prophylactic vaccine consists of ium aluminium hydroxide adsorbed and formalin inactivated cultures of $C$. chauvoei and $P$. multocida gives protective immunity against BQ and HS. Prior to operation in ruminants, proper disinfection of surgical instruments is necessary to avoid infection.

\subsection{Anthrax}

Anthrax is a highly fatal, acute and febrile zoonotic disease. It is enlisted in top five diseases of zoonotic importance in India where attention has to be prioritizing (Sekar et al., 2011). Cattle and sheep are highly susceptible to anthrax followed by horse, mules and pig. It is a soil-borne infection, caused by Bacillus anthracis and outbreaks generally occur after the climatic change. The disease is endemic in south Asia and Bangladesh (Thapa et al., 2014), especially enzootic in India and endemic in Karnataka, Tamil Nadu, Andhra Pradesh, West Bengal, Orissa, Maharashtra and Jammu and Kashmir (Gunaseelan et al., 2011). The "incubator zones" for the presence of anthrax is an alkaline soil $\mathrm{pH}$ and dry periods which provides the microenvironment for spore survival and increased exposure to susceptible hosts. Majority of the disease incidence were encountered in cattle followed by sheep or goat, buffalo, pig and elephant in India. Although the disease is restricted to herbivores, but few sporadic cases from wildlife captive animals like hyena of Nandanvan zoo, Chattisgarh have also been reported in recent past (Patil, 2010). The possible role of the insects like house fly (Musca domestica) in spreading the disease among animals also cannot be ruled out (Fasanella et al., 2010). Beside that another important source of spread of infection is a bone meal which is an essential additive of animal feed as well as in fertilizers; being frequently imported or exported among developing countries (Davies \& Harvey, 1972). The epidemiological data collected during 2002-2010 from bovine outbreaks of anthrax, showed maximum outbreaks of disease in West Bengal, in which 631 animals were affected with disease and 564 animals were died. In small ruminants especially sheep, the highest outbreaks of disease were encountered from Andra Pradesh and Karnataka which might be due to more sheep population in these states and also unresetricted migratory patterns. The important tools for the prevention of anthrax are vaccination, avoiding opening of the carcass, proper carcass disposal, burning of the bush, appropriate treatment, and in order to avert a future outbreak, annual revaccination is necessary for the outbreak area for at least three years (Chelsea et al., 2008). 
3.4 Enterotoxemia (ET)

Enterotoxemia (ET) is a severe disease of ruminants caused by C. perfringens types $\mathrm{B}, \mathrm{C}$ and $\mathrm{D}$ with more case fatality rates results in considerable economic losses to the farmers (Rood \& Cole, 1991). ET is otherwise called as pulpy kidney or overeating disease. The disease affects cattle, sheep, and goats. Sheep and goats of all the age group are affected however younger animals are more prone to infection. The bacteria are usually present in fewer numbers in the intestine of sheep and goats. Where there is sudden change either in food or in the environment, the disease precipitates. Overgrowth of the $C$. perfringens occurs due to excessive consumption of milk or large amounts of grain, immunosuppression, heavy gastrointestinal parasitism, ration rich in carbohydrates and low in roughage, and reduced gastrointestinal motility.

In India, during the commencement of monsoon season, frequent disease outbreaks of enterotoxaemia in sheep were encountered every year, in spite of frequent vaccinations against $C$. perfringens Type D (Kumar et al., 2014). Severe enteritis and sudden death in lambs are caused by type B and C infections. Kumar et al. (2014) reported the prevalence of $C$. perfringens type $\mathrm{C}$ for the first time in India. Major causative agent for enterotoxemia is $C$. perfringens type $\mathrm{D}$ and $\mathrm{C}$. $C$. perfringens type $\mathrm{B}$ and $\mathrm{D}$ produces epsilon toxin, which is responsible for lethal ET (Arya \& Bhatia, 1992). Epsilon toxin is initially secreted as inactive prototoxin, which undergoes trypsin digestion leads to conversion of active toxin by losing N-terminal peptide (Bhown \& Habeeb, 1977).

The mature epsilon toxin is responsible for highly lethal, dermo necrotic and edematous activities. The clinical signs in sheep are colic, diarrhoea and neurological symptoms. Postmortem lesions are widespread vascular congestion, with cerebral, cardiac, pulmonary, and renal oedema (Uzal et al., 2004). A sporadic case of the disease outbreak has also been reported in camel calf with the association of $C$. perfringens type A. During 2006, highest number of outbreak was encountered in India. Majority of the disease outbreaks were recorded from AP, Tamil Nadu, Karnataka, Maharashtra and Jammu and Kashmir. An estimated 12,929 sheep and 619 goats have died due to ET since 2002 (http://www.icar.org.in/files/Vision\%202030_PDADMAS-1101-2012.pdf). In the recent past, the number of disease outbtreaks became reduced significantly due to the efficient vaccination strategies. The animals affected with disease should not be vaccinated, because it will flare up the disease outbreak. The vaccination strategy for young animals includes primary dose at 4 weeks of age and booster revaccination at 1 month later of primary dose and all the adult animals should be vaccinated yearly once. Recently, an inactivated whole-cell vaccine was developed and commercialised for the control and eradication of ET, however major disadvantage of this vaccine is local reactions at the site of inoculation. Recently, for sheep combined aluminum hydroxide adjuvanted epsilon toxoid (recombinant) and live attenuated freeze-dried sheep pox vaccine is developed (Chandran et al., 2010).
3.5 Brucellosis

Brucellosis is one of the five main notifiable bacterial diseases of zoonotic importance in the world. Brucellosis is a disease of animals with humans as an accidental host (Joshi \& Parkash, 1971). Brucella is a Gram-negative facultative intracellular bacteria and bovine brucellosis is caused by $B$. abortus, less frequently by $B$. melitensis and rarely by $B$. suis. Cattle and buffaloes harbor predominantly $B$. abortus biotype-1; followed by biotype-3; rarely biotypes-2, 4, 5, 6 and 9 (Renukardhya et al., 2002). Out of 6 Brucella spp., B. melitensis, B. abortus, B. suis and $B$. canis can cause infection and clinical symptoms in man in the descending order of pathogenicity (Smits \& Kadri, 2005). The disease has been eradicated from the livestock populations of most European countries, Japan, Canada and the USA. The disease is highly endemic in different states of the country and reported in different animal species like cattle, buffalo, sheep, goats, camel, yak and pig (Smits \& Kadri, 2005). But, the highest prevalence is seen in dairy cattle. There are various reasons of its endemicity viz. ignorance of carrier animals, ineffective test and slaughter policy in most of the Indian states, improper and unplanned vaccination, no effective quarantine and uncontrolled trans-state migration of animals (Renukaradhya et al., 2002). By seeing the intensification of disease in recent past, it seeks to review the ongoing policies implemented for its eradication and/ or control. Bovine brucellosis is now have been eradicated from many countries but as it is still prevailing in many states of our country; we are lagging behind in various ruminants' production like milk and meat etc. (Singh et al., 2015a).

In India, brucellosis was first recognized in 1887 and since then the cases are being observed in almost all the states of the country. In India, on an average, the disease causes revenue losses of INR 420 per cattle, INR 1100 per buffalo, INR 42 per sheep, INR 30 per goat and INR 36 per pig with the total economic loss of Rs. 350 million. It is also reported from the Yak (Renukaradhya et al., 2002; Bandyopadhyay et al., 2009b; Singh et al., 2015a). Higher prevalence of disease was reported from goats in Bihar and Madhya Pradesh states and in sheep Rajasthan and Karnataka states of India. The overall prevalence of disease was $8.85 \%$ in goats and $6.23 \%$ in sheep in India (Joshi et al., 1975; Chatterjee et al., 1986; Suresh et al., 1993; Gill et al., 2000; Renukardhya et al., 2002; Hemadri \& Hiremath, 2011). In spite of significant improvements made in diagnosis and therapeutic advances, brucellosis emerged as a widespread and highly prevalent disease in many developing countries. The sero-epidemiologial data collected during 1994 to 2001 from various states of India revealed that the disease in cattle and buffalo was more prevalent in Union Territory of Delhi followed by Andaman and Nicobar islands, West Bengal, Tamilnadu, Kerala, Gujarat, Maharashtra and Punjab. The annual sero-prevalence data reveals increasing trend of the disease in India. The representative samples collected from different states of the country showed that the prevalence rate become increased from $34.15 \%$ during $2006-07$ to $67.28 \%$ during 2010-11 (Gill et al., 2000; Renukaradhya et al., 2002; Hemadri \& Hiremath, 2011). Control and management of 
animal brucellosis include careful herd management, hygiene, and vaccination. Many countries attained brucella free status by employing test and slaughter policy. However, in India, only "test and segregation" policy is practically adaptable to control the disease in conjunction with efficient preventive measures and control of animal movements. Vaccination is the practical, feasible and effective approach for the control of brucellosis in our country. Hygienic disposal of uterine discharges, foetus, foetal membranes is required. Increased public awareness through health education programmes is necessary. Vaccination with B. abortus strain 19 vaccine (Bruvax; Indian Immunologicals Limited, Hyderabad) is in use for female cattle and buffalo calves between 4 to 6 months of age followed by annual revaccination and all adult females just after parturition. The advantages of calf hood vaccination are the prevention of abortions in the herd produces short-lived antibody response up to 6 to 8 months after vaccination, no booster vaccination required and builds herd immunity in 3-5 years period. The vaccine should not be administered to pregnant animals, bulls and male calves (Kulshreshtha et al., 1978; Renukardhya et al., 2002; Hemadri \& Hiremath, 2011; Shome et al., 2012).

\subsection{Leptospirosis}

Leptospirosis is a re-emerging zoonotic disease in Asia especially in India, Africa and Latin America and widespread in those countries having a hot and humid temperature. Till date, 210 pathogenic Leptospira serovars have been identified which have been placed into 24 serogroups based on antigenic similarity. The genus Leptospira consists of 2 species known as $L$. interrogans and $L$. biflexa. The pathogenic species are $L$. interrogans, L. borgpetersenii, $L$. inadai, L. meyeri, $L$. noguchii, L. santlilrosai, L. weilli, L. wolbachii, L. fainei, $L$. alexanderi, $L$. parva and $L$. kirschneri. $L$. biflexa is the saprophytic species. Most commonly reported serovars responsible for the infection in man and animals are Autumnalis, Icterohaemorrhagiae, Canicola, Pomona, Grippotyphosa, Hebdomadis, Australis, and Hardjo. These serovars have been also commonly reported from wild animals and natural carriers such as rodents (Srivastava, 2008; Himani et al., 2013). The disease leptospirosis was first reported in 1988 as Andaman haemorrhagic fever. It has attained significant consideration in recent past as the incidences are being increased among various livestock species in India. Leptospirosis is endemic in India, from 20th century onwards and many outbreaks of disease have been encountered in coastal regions of West Bengal, Maharashtra, Gujarat, Tamil Nadu, Kerala, Orissa, Karnataka and Andaman and Nicobar Islands (Varma et al., 2001). Majority of the disease incidences are happening between October to November which correlates with the monsoon season. The disease was initially reported from Indian cattle by Adinarayanan et al. (1960). Subsequently, several other workers also reported its incidence and prevalence (Srivastava et al., 1991; Varma et al., 2001; Sivaseelan et al., 2003).
The disease is of significant economic importance in terms of losing livestock through abortions and increasing treatment cost for repeat breeding cases. The disease mostly precipitates with the monsoon season. The reservoir for the etiological agent is rodents in principal along with cattle, pig, and dog. Sero-epidemiological data of leptospirosis conducted during 1995 from different states of India revealed that highest prevalence in dogs $(15.9 \%)$ followed by horses (14.6\%), sheep $(12.5 \%)$, cattle $(7.5 \%)$ and buffaloes $(5.4 \%)$ (Srivastava et al., 1991; Sivaseelan et al., 2003; Srivastava, 2008). During 2007 outbreak in Karnataka, a total of 1,516 cases and southern parts of Gujarat in 2011, 130 deaths within a span of two months were reported (http://www.gideononline.com; Promed, 2011). Recently, 209 cases of disease with 12 cases of deaths in Kochi and Kerala, and 16 deaths from districts of Surat and Valsad of Gujarat were recorded in October 2012 (http://www.healthmap.org). A seroprevalence rate of $71.12 \%$ was reported from Kerala where highly prevalent serovar is Leptospira interrogans serovar Autumnalis followed by Australis, Pomona, Canicola, Pyrogenes, Icterohaemorrhagiae, Javanica and Patoc (Ambily et al., 2013). These alarming reports highlight the constant risk of leptospirosis and emergence of new serovars other than the vaccine serovars demands the inclusion of these serovars in the vaccines due to serovar-specific immunity in leptospirosis (Sambasiva et al., 2003).

Since leptospires are fastidious and slow growing organisms, isolation of organism is difficult due to 6 weeks required for organisms to grow. Most widely used test for diagnosis of leptospirosis is microscopic agglutination test (MAT) and a titre of 1:100 or more indicates infection in seroprevalence studies (Srivastava, 2008; Himani et al., 2013). The prevention and control of leptospirosis in domestic animals and man are difficult to achieve due to the widespread distribution of leptospires in wildlife and long-term carriers. The diseased animals should be immediately isolated for at least 2 weeks and the premises should be thoroughly disinfected. The carrier animals shedding the organisms in the urine should preferably be slaughtered and buried or burnt.

Since leptospirosis is an occupational hazard all the persons directly involved with animals or its environment should use gumboots, gloves, aprons etc. Rodent control using rodenticides, better hygienic practices and environmental hygienic measures to avoid the risk of water, soil and food contamination are necessary to check the transmission of leptospirosis (Sambasiva et al., 2003; Srivastava, 2008; Himani et al., 2013; Patil et al., 2014). Although in wild animals vaccination is not possible, and in domestic animals vaccination strategy can be applied for control and prevention of leptospirosis using outer membranes of bacteria and/or whole cell inactivated with chemical agents (Palaniappan et al., 2002). 


\subsection{Listeriosis}

Listeriosis also known as circling disease, silage disease and meningoencephalitis, and a fatal disease of ruminants like sheep, goat, cattle, buffalo, camel, and non-ruminants like horse, pig, canine, rodent, wild animals, birds and also humans (Malik et al., 2002; Barbuddhe et al., 2012; Dhama et al., 2013a, 2015a). Among small ruminants sheep are mostly susceptible. Recently, listeriosis caused 23,150 illnesses, 5463 deaths and 172,823 disability-adjusted-life-years worldwide (De Noordhout et al., 2014). It is an important foodborne zoonotic disease caused by intracellular pathogen Listeria monocytogenes, which does cell to cell entry results in the crossing of blood-brain, intestinal and placental barrier (Hernandez-Milian \& Payeras-Cifre, 2014; Dhama et al., 2015a). The organism can survive at various temperatures ranges from 4 to $37{ }^{\circ} \mathrm{C}$ (Janakiraman, 2008). The organism has several virulence factors like internalins, hemolysin, metalloprotease, listeriolysin-O (LLO), fibronectin-binding protein-A (FbpA), phospholipases and bile exclusion system which are necessary for intracellular multiplication, adhesion and pathogenisis (Vera et al., 2013). The disease occurs as sporadic or epidemic form throughout the world; however during an outbreak, it causes severe damage (Dhama et al., 2015a). Mostly the disease in animals occurs as subclinical but severe forms can also occur. The clinical manifestations of listeriosis include septicaemia, meningoencephalitis, abortion with placentitis in last trimester, stillbirth, perinatal infections and gastroenteritis (Janakiraman, 2008; Barbuddhe et al., 2012; Limmahakhun \& Chayakulkeeree, 2013; Dhama et al., 2015a).

Listeriosis has unique seasonal occurrence during December to May in northern hemispheres due to the seasonal feeding of silage. More cases of abortions in sheep occurs during February and March due to late pregnancies. In humans, mortality due to listeriosis varies from 20-30\% (Barbuddhe et al., 2012; Dhama et al., 2013a, 2015a). Listeriosis can be transmitted by ingestion of feed and water contaminated with saliva, nasal secretions, faeces and aborted materials from infected animals and also inhalation of dust and soil contaminated with bacteria (Brugere-Picoux, 2008). Ready-toeat foods and animal origin foods like milk, meat, and their products play a crucial role in the transmission of listeriosis to humans (Rebagliati et al., 2009). Young lambs (under 5 weeks of age) will suffer from septicemic form while the encephalitic form is noticed in older lambs (4-8 months). It causes abortion and stillbirth in pregnant women and in foetuses it causes abscesses and granulomas in various organs like lungs, liver, and spleen (Drevets \& Bronze, 2008). In India, genital listeriosis is very common and correct epidemiological data are not available due to under-reporting and poor diagnostic facilities (Malik et al., 2002). Studies regarding the prevalence of Listeriosis in various developing countries are necessary to identify the accurate status of disease throughout the world (De Noordhout et al., 2014). Treatment of listeriosis is a difficult task due to the invasion of all cell types. Drugs of choice for listeriosis are erythromycin and ampicillin. Control of listeriosis is difficult due to ubiquitous nature of bacteria in the environment, lack of a simple method for identification of Listeria and poor understanding of risk factors except silage (Malik et al., 2002). Good management practices like proper disposal of contaminated materials, beddings and litters, and infected carcasses should be done carefully by incineration or burning methods. Consumption of unpasteurized milk or uncooked meat should be avoided (Rebagliati et al., 2009).

\subsection{Tuberculosis}

Bovine tuberculosis (bTB) is a chronic bacterial zoonotic disease and easily spreads to humans through inhalation of aerosols or ingestion of unpasteurized infected milk (Prasad et al., 2005). Tuberculosis is caused Mycobacterium tuberculosis complex (MTC) belongs to the genus Mycobacterium. MTC has four species namely, M. tuberculosis, M. bovis, $M$. africanum and M. microti. M. tuberculosis mainly affects humans, whereas $M$. bovis causes bovine tuberculosis and affects wide host range including domestic as well as wild animals (Grange, 2001; Verma et al., 2014a). The bTB is widely prevalent and causes $10-25 \%$ loss in productivity (Verma et al., 2014b). In developing countries, there is increased the incidence of $M$. bovis infection in humans causing serious public health problem due to sharing of the same habitat in domesticated animals and humans (Grange, 2001). In Africa, bTB endemic zones nearly $85 \%$ of cattle and $82 \%$ of the human populations were living together (Michel, 2002). Organisms are excreted in exhaled air, sputum, faeces, urine, milk, vaginal and uterine discharges, and discharges from open peripheral lymph nodes (Verma et al., 2014a). There are limited reports available from India and many epidemiological and public health aspects of the infection remain largely unknown (Neeraja et al., 2014a; Neeraja et al., 2014b; Baqir et al., 2014; Verma et al., 2014b). An overall prevalence of bTB in India is 14.31 to $34.42 \%$ (Thakur et al., 2010). M. bovis mainly causes extra-pulmonary forms of tuberculosis and major route of transmission is the oral route. Bovine tuberculosis has been classified as list B disease by OIE due to various socio-economic and public health concerns at the national level as well as the international trade of livestock and their products.

Various wild animals like badgers, brushtail possums, deer, bison and African buffalo play an important role in the maintenance of $M$. bovis infection in wildlife communities and the spread to domestic animals. The test and slaughter policy is effective for tuberculosis control, however in India difficult to follow due to various social and economic constraints and the existence of more wildlife reservoir. In the early stage of infection, test and segregation are recommended while in the terminal stage of infection, test and slaughter is followed. Hence, it is difficult to eradicate bTB infection from livestock until transmission between wildlife and domestic animals has prevented. Better diagnostic tests for rapid screening of disease at the field level should be developed (Sandhu, 2011). The main diagnostic test used for screening of bovine tuberculosis is the tuberculin test (Baqir et al., 2014; Neeraja et al., 2014a; Neeraja et al., 2014b). For control of bTB in India requires 
vaccination in livestock and captive wildlife species with collaborative efforts between agriculture, wildlife, environmental and political authorities. Pasteurization of milk before marketing and organized abattoirs with carcasses can be routinely tested for TB (Sandhu, 2011). Bacillus of Calmette and Guerin (BCG) vaccine is used for $\mathrm{TB}$, which is a live, laboratory-attenuated strain of M. bovis (Waters et al., 2014).

\subsection{Paratuberculosis (or) Johne's disease}

Paratuberculosis also known as Johne's disease (JD) is infectious, chronic granulomatous enteritis of cattle and buffaloes caused by Mycobacterium avium subspecies paratuberculosis (MAP) (Singh et al., 2014b). JD is a deadly, emaciating and chronic wasting disease characterized by weight loss and profuse diarrhoea. JD mainly affects domestic and wild ruminants and poses serious economic loss to the dairy industry. JD is endemic in farms throughout the country. Most of the time, the disease unnoticed due to chronic nature of the disease and unfamiliar symptoms to the clinicians and farmers (Tripathi, 2008). It is a zoonotic disease and causes Crohn's disease (CD) in humans (Greenstein, 2003). High prevalence of MAP antibodies (Indian bison type) was recorded from animal attendants having gastrointestinal problems, who were worked in endemic JD infected goat flocks in India (Singh et al., 2008b). CD is a non-specific chronic inflammatory condition of the gastrointestinal tract and clinical signs are reduced appetite, bloody diarrhoea, abdominal pain, vomiting, tiredness and weight loss. JD is a list B of OIE listed disease and animals require certification due to trade restrictions. It is calculated that almost $40 \%$ of US dairy herds are infected with JD and economic losses exceed 1.5 billion/year in dairy industry (Wells \& Wagner, 2000). Animals are often infected during early life by faecal oral route. The Mycobacterium infect the $\mathrm{M}$ cells of the follicle in intestinal epithelium and then engulfed by intestinal macrophages leads to replication and viable for several months to years and development of disease (Momotani et al., 1988; Tripathi, 2008).

The disease was first reported in cattle in Lahore of undivided India, followed by another case in 1917 from a Military Dairy Farm, Hisar. Since then, many cases have been reported throughout the country with an incidence rate of 1.78 to $1.9 \%$. MAP infecting the animals in North India has been genotyped as Bison type (Sevilla et al., 2004; Sevilla et al., 2005). High seroprevalence of JD average $29 \%$ (29.8\% in cattle and $28.6 \%$ in buffalo) has been found in domestic animals by using indigenous, sensitive and MAP-specific ELISA kits in North India. The seroprevalence of JD in Uttar Pradesh $(31.9 \%)$, Punjab (23.3\%), Gujarat (13.39\%) and Andhra Pradesh $(16.26 \%)$ has been reported (Sivakumar et al., 2005; Tripathi, 2008; Singh et al., 2011; Mohan et al., 2013). In spite of very high morbidity rates and lower productivity, economic losses in production go unnoticed in India due to chronicity. The insertion element IS900 has been regularly used to identify the MAP in clinical samples (Garg et al., 2015). Management and control of JD are difficult due to the absence of rapid and sensitive diagnostic test for diagnosis of infected animals before clinical signs develop. Due to chronic nature of the disease, it is necessary to diagnose the infection early to decrease the production losses and to avoid the infection spread to susceptible animals and humans (Tripathi, 2008).

\section{Parasitic diseases of ruminants}

\subsection{Fascioliasis}

Fascioliasis is caused by Fasciola gigantica and $F$. hepatica. In India, fascioliasis is more common caused by $F$. gigantica. Fascioliasis is more common in sheep and causes high economic loses to sheep rearing farmers. The incidence rate of fascioliasis in various climatic regions like tarai, hills and plains in northern region of India was recorded as $10.79 \%$ in cattle, $13.90 \%$ in buffaloes, $2.78 \%$ in sheep and $2.35 \%$ in goats (Sharma et al., 1989; Garg et al., 2009). One of the studies conducted in Gorakhpur district showed that about $94 \%$ of the buffaloes are infected with $F$. gigantica (Singh \& Agarwal, 1981). Lymnaea acuminate has been identified to be the intermediate host (Agarwal \& Singh, 1988). Livestock of Tarai region is having the maximum incidence of fasciolosis when compared to hills and plains (Malone et al., 1998). In cattle and buffaloes, high prevalence of disease was noticed during winter months ( $15.57 \%$ buffaloes, $11.84 \%$ cattle) followed by summer and rainy season.

However, in sheep and goats, high prevalence of disease (2.71\% goats and $4.60 \%$ sheep) was noticed during rainy season. An Abattoir studies exhibits its more prevalence in buffaloes $(31.14 \%)$ when compared to sheep and goats (Garg et al., 2009; Mir et al., 2013; Swarnakar \& Sanger, 2014). Further, $5.48 \%$ of Lymnaea auricularia snails were carrying the immature stages of $F$. gigantica. The snails present in the Tarai region causes higher incidence $(7.28 \%)$ of disease when compared to snails present in plains (1.57\%). During 2002, higher incidence of Fasciola was recorded from Orissa with a total of 545 outbreaks, in which 4993 animals were affected and 34 animals were died, followed by Haryana, Manipur, Mizoram, and Bihar. Nationwide fascioliasis collective data shows outbreaks were maximum in Orissa followed by Bihar, Mizoram, Rajasthan, Haryana, Kerala, Karnataka, Maharashtra, Tamil Nadu and Gujarat (Gupta et al., 1986; Sheikh et al., 2007; Hemadri \& Hiremath, 2011).

One of the methods to control the disease is to effectively control the snail population (Kumar et al., 2009). In a present era which is more concern with the environment pollution, the researcher should exercise in the direction to identify more such products which are of plant origin as well as to ensure about its biodegradability. The experiments conducted by some workers under this direction had shown proven activity of some plants like Alstonia scholaris, Thevetia peruviana, Euphorbia pulcherima and Euphorbia hirta act as snailicidle (Singh et al., 2010). 
4.2 Trypanosomiasis

Trypanosoma evansi causes Trypanosomiasis, which is a significant haemoprotozoan infection of wild animals, dogs, horses, camels, donkeys, cattle and buffaloes. The outbreaks are reported in water buffaloes in India (Tewari et al., 2013; Pandey et al., 2015). The disease was originated from North Africa and through the Middle East it reaches into India (Desquesnes et al., 2013). All domestic animals except camels, the disease is commonly known as Surra and in camels the disease is known as Tibersa. T. evansi is the most commonly occurring trypanosome species in India and causes major economic losses in horses and camels (Tewari et al., 2013). Tabanidae flies (Horse flies and Deer flies) are the vectors responsible for the spreading of the disease. There are 244 species of this vector reported in India (Banerjee et al., 2015). In dogs, the prevalence of $T$. evansi was observed higher in Mongrel than that of other recognized breeds. The young ones below 2 years of age are more commonly affected (Prasad et al., 2015). Absence of the disease transmitting vector is the major reason for non-prevalence of other trypanosome species. Due to subclinical infection, the incidence of trypanosomiasis in cattle and buffaloes has been unnoticed in India and buffaloes may act as reservoirs (Jaiswal et al., 2015). When the animals become stress due to long transportation, hard work, overcrowding, malnutrition, inclement weather and other concurrent infections, the infection flare up and become prominent and visible infection (Rani et al., 2015). The acute form of the disease in bovine is manifested as emaciation, high fever, lachrymation, corneal opacity, reduced milk yield, nervous signs and mortality often happens within 24 hours of onset of clinical signs. Chronic Surra is characterized by weight loss with loss of reproductive performance (Radostits et al., 2007). In addition to economic losses, the disease also causes immune suppression along with huge mortality in precious animals. The disease occurs in all age groups of animals. The incidence of infection is more common during 1.5 to 2 months after rain, because more availability of rain water lodged breeding areas for disease spreading vectors (Rani et al., 2015). Highest incidence of disease was reported during 2001-02 whereas least incidence of disease was reported during 2009-10. The researcher should more focus on the development of novel chemotherapeutic agents having selective and promising therapeutic potential (Sivajothi et al., 2013). T. evansi can be controlled by using trypanocidal drugs, control of vectors and trypanotolarent cattle breed development (Tewari et al., 2013). Diminazene aceturate $(7 \mathrm{mg} / \mathrm{kg} \mathrm{b}$. wt) is the prescribed drug for the treatment of trypanosomiasis in ruminants and should be administered deep intramuscularly.

\subsection{Theileriosis}

Bovine tropical theileriosis is an inapparent disease in large ruminants, caused by Theileria annulata and highly fatal diseases of indigenous cattle breeds and cross breeds due to extensive cross-breeding programmes. T. annulata and $T$. parva are considered to be the most pathogenic species of Theileria. The incidence rate of T. annulata is $14.94 \%$ by blood smear examination whereas, 30 to $60 \%$ of seropositivity was reported in cross-bred cattle in India, except Himalayan region due to unfavourable climate for tick survival (Singh et al., 1993; Naik et al., 2010; Kohli et al., 2014; Kumar et al., 2015b). Theileriosis causes a serious economic loss due to mortality and reduced milk yield. In India, the tropical theileriosis is one of the major hurdles in genetic improvement programme of Indian taurus cattle breed. The estimated economic loss due to theileriosis is approximately 800 million US dollars (Devendra, 1995). The incidence of disease is seasonal due to availability of ticks on the host, which carries the organism, was higher during summer months like May to October. Other predisposing factors favouring the occurrence of disease are stress, harse climate, concurrent disease, transportation and vaccination. Hyalomma anatolicum anatolicum trnamits $T$. annulata, which is normally present in the semi desert desert and steppe. Adult and its immature stages of three host tick were present in cattle. The adult stages of tick were more active during late spring season. The immature phase of tick usually feed on on the animals, and nymphs and larvae can obtain the disease by feeding on the infected animal and transmit the disease to other animals following moulting, adults or nymphs feed on other animals. The incidence of the disease is higher during March to November because this is adult feeding season; however, the nymphs have the feeding season of July to September. The occurrene of $T$. annulata is higher during late spring and early summer season (Roy et al., 2004; Magona et al., 2011; Vahora et al., 2012; Kohli et al., 2014). The epidemiological data reveals that the highest number of outbreaks was occurred from Orissa followed by Bihar, West Bengal, Jharkhand and Haryana. In India, on nucleotide heterogeneity study, it was observed that in $T$. annulata there is a strain variability as hetrogenicity varies between 0.1 to 8.6 . Therefore, it is also required to go for an elaborative study on the genetic diversity of the parasite which is an overlooked area till now (George et al., 2015). The disease epidemiological data showed that the incidence of disease was low during 2008 whereas the incidence was more during 2006 (Hemadri \& Hiremath, 2011).

\subsection{Babesiosis}

In India, babesiosis in bovines is mainly caused by Babesia bigemina and Babesia bovis. The disease is prevalent in many states of the country like U.P., Orissa, Kerala, Punjab, Arunachal Pradesh, Mizoram, Meghalaya and Assam (Ravindran et al., 2002; Wadhwa et al., 2008; Singh et al., 2009a; Sharma et al., 2013; Saravanan et al., 2013). The Babesia is transmitted to the susceptible animal by Boophilus microplus, which is the one host tick. Transovarial route is the major mode of spread within the tick. The infected female adult tick can spread the disease up to 32 generations. There are some novel serological tests like slide enzyme-linked immunosorbent assay (S-ELISA), indirect fluorescent antibody test (IFAT) and molecular test like PCR available for the detection of the disease in bovines (Singh et al., 2009a; Harkirat et al., 2013). 
The disease epidemiological data showed that incidence of disease was more during 2001, whereas incidence of disease was less during 2008-09. The analysis of the epidemiological data reveals that the incidence of the disease were maximum in Orissa followed by Assam, Haryana, Jharkhand, Bihar, Madhya Pradesh, Rajasthan and Himachal Pradesh (Ananda et al., 2009; Singh et al., 2012). Different diseases of ruminants and the species affected are presented in Fig. 1.

\section{Emerging Diseases}

Recently, many outbreaks of emerging diseases like bovine spongiform encephalopathy (BSE), paramyxovirus infection in pigs (Nipah) and horses (Hendra), severe acute respiratory syndrome (SARS), rabies, tuberculosis, bovine corona virus, Lyme disease, Crimean-Congo hemorrhagic fever, West Nile virus and zoonotic $\mathrm{H} 5 \mathrm{Nl}$ avian influenza were detected, which causes significant morbidity and mortality in the developing world (Hansa et al., 2013; Verma et al., 2014a; Goswami et al., 2014; Madhu et al., 2016). Many diseases re-emerge with new strains that facilitate them to escape from present control measures. Emerging and re-emerging diseases arise due to genetic changes because of immunological pressure and recombinantions with other viral or cellular genes. Currently, microbes and concerned vectors are changing themselves because of continuous change in agriculture versus animal husbandry practices. A faster mode of trades of animals and their products have facilitated the spread of microbes and the vectors involved; to newer zones of territories. The possibilities of emergence of vector borne diseases can also be co-related with air travelling (Kumar et al., 2015a). Because of high urbanization, forest area is constantly shrinking which may result to lead more interaction between human, captive and wild lives resulting in emerging novel microbes. Sometimes, already existing organisms may transform into an actually novel, and until now unidentified organisms. Emerging diseases are more threatening to ruminants because of less information available about their origin, magnitude of economic losses as well as epidemiology. Recently, numerous resistant bacteria to many drugs are arising with unique pathogenic potential for human through food chain like Campylobacter, Salmonella enterica, Enterococcus spp. etc (Mishra et al., 2011; Kumar et al., 2015a).

\section{Exotic Diseases}

There has been a constant risk of emergence of novel pathogens/ diseases into a disease free country results in a grave effect on animal health due to high morbidity and mortality. Exotic (non-native) diseases/organisms, once entered into a country, can become more intense into an epidemic as being overlooked by the veterinarians due to its non-recognition or being prejudice of its non-occurrence. The disease may also intensify due to non-availability of suitable drugs or vaccine for control, the absence of disease resistance in the host and inadequate facilities in diagnose and limiting the spread of the disease.

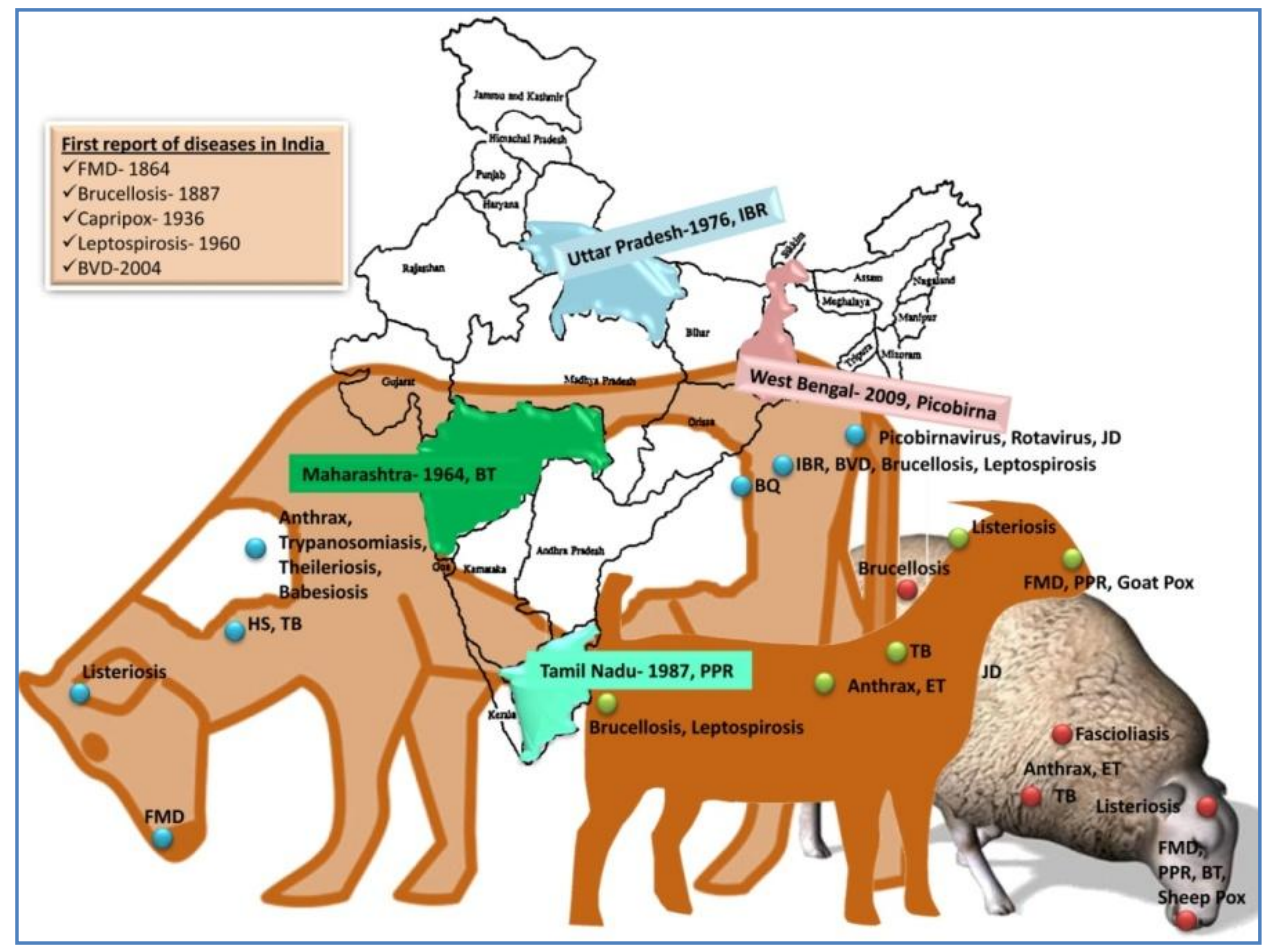

Figure 1 Disease map and ruminant species affected. Different diseases and the species affected are shown in the figure. Map also represents the place and year of few diseases reported for the first time in India. 
Therefore, it is needed to put extra precaution while importing the animals from disease suspected countries, which may harbour the pathogens. The WTO has granted permission to take legal actions in countries to implement their sovereign rights to save their livestock from fatal diseases (Bayry, 2013; Kumar et al., 2015a).

\section{Diagnosis of animal diseases}

A tentative diagnosis of the diseases can be done on the basis of clinical signs, species affected, epidemiological pattern, post-mortem lesions and laboratory confirmation by isolation of etiological agent, various serological and molecular methods. Serological tests such as counterimmunoelectrophoresis (CIE), agar gel immunodiffusion test (AGID) or agar gel precipitation test (AGPT), ELISA, complement fixation test (CFT), serum or virus neutralization test (VNT), hemagglutination (HA) and hemagglutination inhibition (HI) test are often used for diagnosis. Virus isolation, immunohistochemical detection, immunoperoxidase test (IPT) and indirect immunofluorescence test (IFAT), RT-PCR, real-time RT-PCR and nucleic acid hybridization are also commonly used for diagnosis of diseases (Rajeev et al., 2011). The novel proteomic techniques interventions like 2-D gel electrophoresis, HPLC and MALDITOF have also given better insight to the disease diagnosis by characterizing the microbes' aetiology (Balamurugan et al., 2014; Chakraborty et al., 2014; Dhama et al., 2014a).

\subsection{Conventional tests/assays}

The major disadvantage of the conventional assays is more labour and time consuming, less sensitive hence not suitable for proper diagnosis, however, used for secondary confirmatory diagnosis and retrospective epidemiological studies. To overcome the disadvantages of conventional assays, novel molecular biological techniques like real-time RT-PCR, loop-mediated isothermal amplification (LAMP) assays, and real-time LAMP have been developed and used frequently for the rapid and sensitive diagnosis of infectious RNA and DNA from clinical materials at nano and picogram level (Rajeev et al., 2011; Sharma et al., 2015). Out of these, for the diagnosis of the diseases, isolation of the microbes stands the gold standard. Virus/ bacterial isolation always cannot be performed as routine diagnostic tests since they are cumbersome, time-consuming, and need cell culture or other selective growth media facilities. Beside that the chances of missing the organism are more due to unfair handling while processing the samples. The traditional culture techniques are also not as sensitive as molecular tools like RT-PCR (Balamurugan et al., 2014; Chakraborty et al., 2014; Dhama et al., 2012).

Several researchers are undergoing towards the development of molecular diagnostics tools for the early, rapid and specific detection of diseases. For serological diagnosis of diseases and mass screening of samples for seromonitoring or serosurveillance or clinical prevalence, ELISA is a rapid, simple and sensitive assay. MAb-based competitive ELISA (cELISA), immunocapture ELISA, sandwich ELISA (s-ELISA), simple and aqueous phase ELISA (SNAPELISA) and blocking ELISA (B-ELISA) are often used for disease diagnosis. ELISA has a higher diagnostic sensitivity and specificity for detection of antigen/antibody in samples (Afshar et al., 1989; Afshar, 1994; Balamurugan et al., 2014; Chakraborty et al., 2014).

\subsection{Molecular diagnostic techniques}

Due to the advent of improved biotechnological tools results in better understanding of the genome of pathogens and nucleic acid-based specific and sensitive assays were developed.

\subsubsection{Nucleic acid hybridization}

Nucleic acid hybridization has been widely used for the identification and differential diagnosis of diseases with the limitations of cumbersome and time-consuming, and feasible for regular diagnosis with number of samples. Despite high sensitivity, radio-labelled probes were not broadly used due to a short half life of 32P, the risk of biohazard needs isotopes handling facility and fresh samples. To overcome disadvantages of radio-labelled probes, non-radioactive probes were developed using digoxigenin (DIG) labelled oligonucleotides or biotinylated DNA. This test provides very specific and rapid results moreover its sensitivity is also not less than that of radioactive labelled probes (Rajeev et al., 2011; Sharma et al., 2015). Some more advance assays like Fluorescent in situ hybridisation (FISH) can also be used to localise the targeted nucleic acid sequences within the cellular material (Balamurugan et al., 2014; Chakraborty et al., 2014).

\subsubsection{Polymerase chain reaction (Nucleic acid amplification)}

RT-PCR has been commonly used for detection and differential diagnosis of diseases. The two-step and one-step RT-PCR has been commonly used for the rapid diagnosis of RNA and DNA in the clinical samples in a single step, which has the capability to replace the existing PCR. A highly sensitive RT-PCR-ELISA for the diagnosis and differentiation of diseases has been developed using RT-PCR product labelled with DIG. The test can identify viral RNA with a titre minimum of 0.01 TCID50/100 $\mu$ l in the infected tissue culture fluid. PCR-ELISA is 10,000 times more sensitive than RTPCR for identification of early and late stages of infection (Rajeev et al., 2011; Sharma et al., 2015). For rapid specific detection and quantification of antigen, real-time PCR techniques targeting genes of pathogens was developed using SYBR Green or TaqMan hydrolysis probe, which is highly sensitive. Multiplexing of Real Time PCR technique can curtail the time further as able to quantify more than single aetiology in one run (Afshar et al., 1989; Afshar, 1994; Balamurugan et al., 2014; Chakraborty et al., 2014; Dhama et al., 2012). 
7.2.3 Pen-side tests

In the recent years, rapid, simple, specific and highly sensitive novel field diagnostic device known as latex beads based agglutination tests (Rana et al., 1999) and LAMP (LoopMediated Isothermal Amplification) were developed. This test provides a rapid and sensitive diagnosis in a rural environment, where no laboratory equipment was available. LAMP can be performed where thermocyclers cannot be easily maintained/ procured (Rekha et al., 2014). The advantage of these tests is no need of agarose gel electrophoresis. Lateral flow test (Arun et al., 2014), simple dot-ELISA, dipsticks, immunofiltration, and antigen-competition ELISA were developed for the diagnosis of antigen/antibody in samples. These tests can be used for screening of large number of clinical samples and suitable for animal disease diagnosis in the field and can be used as a pen-side test for identification of disease. A suitable LAMP test was developed for the diagnosis of Mycoplasma agalactiae the causative agent of contagious agalactia in goats with the detection level of $20 \mathrm{fg}$ DNA. The test could be performed with $70 \mathrm{~min}$. at $58^{\circ} \mathrm{C}$ constant temperature (Rekha et al., 2015). These assays had high diagnostic sensitivity and specificity and bear the advantages of rapid, user-friendly, more economic and do not need technical skill or expertise (Balamurugan et al., 2014; Chakraborty et al., 2014; Dhama et al., 2014b; Sharma et al., 2015).

\subsubsection{Recombinant antigen-based assays}

Nowadays, production of recombinant proteins becomes simple and more efficient, due to the progression of recombinant DNA and gene expression technology. Due to the advantage of genetic modification, the quality and quantity of recombinant proteins became improved and the maintenance of post-translational modifications usually determines the choice of the host systems. Various efforts have been made to develop the different expression systems like bacterial, mammalian, yeast and insect cells for expression of different proteins of pathogens and to evaluate the possible use of recombinant proteins in different diagnostic tests. The limitations lay here with that of biosafety issues which need to be taken utmost care (Balamurugan et al., 2014; Chakraborty et al., 2014; Sharma et al., 2015).

\subsubsection{Nanotechnologies}

The tests involved here are able to detect molecular interactions. The benefits of such tests are their smaller dimensions by using nanoarrays and nanochips as platforms. Another superiority of such arrays is their potential to analyse a sample for an array of all the probable infectious agents which are having common overlapping clinical signs in single DNA chip. The technique is of use in detecting Influenza strains and vesicular viral diseases. Beside that the nanoparticles like gold nanoparticles, nanobarcodes, quantum dots (cadmium selenide) labelled antibodies/ antigens are also used for identification of specific pathogens or molecules
(Rajeev et al., 2011; Balamurugan et al., 2014; Chakraborty et al., 2014; Sharma et al., 2015).

\subsubsection{Biosensors}

Biosensors based assays are the tools used either to detect antigen or an antibody. In such assays, there is a use of receptor (antibody) as well as a transducer which converts a biological interaction reaction into a quantifiable signal. The common transducer technologies are electrochemistry, fluorimetry, reflectometry and/ or resonance. The Biosensors are attached to very high sensitive instruments able to capture readable signals. The limitations of such applications are as it needs high skilled persons for interpretations of the result, the high cost of equipment and high sample processing charges (Balamurugan et al., 2014; Chakraborty et al., 2014; Rajeev et al., 2011; Sharma et al., 2015). Diagnostic techniques used for the diagnosis of different diseases along with their merits and demerits are presented in Fig. 2.

\section{Strategies for prevention, control and eradication of diseases}

Generally, for prevention, control and eradication of infectious diseases, strict biosecurity measures, quarantine, and isolation of infected and disease suspected animals should be appropriately implemented. Added these, effective disease surveillance, monitoring and networking programmes with suitable vaccination and treatment strategies are of utmost importance for the successful control of various diseases (Dhama et al., 2013b; Dhama et al., 2014b; Verma et al., 2014b). Supported with conventional diagnostic tools, recent advancements in diagnostics viz., multiplex PCR, LAMP, biochips, microarrays, nanotechnology, gene sequencing and phylogenetic analysis need to be strengthened for early and confirmatory diagnosis of ruminant diseases (Kawadkar et al., 2011; Dhama et al., 2012; Dhama et al., 2014a; Dhama et al., 2014b; Hurk \& Evoy, 2015; Karthik et al., 2016).

Together with conventional live and killed vaccines in practice, recent advances in the field of vaccines and vaccinology need to be exploited to their full capacity to counter important diseases of ruminants and help alleviate economic losses of animal producers. These include DNA vaccines, subunit vaccines, recombinant vaccines, plant/edible vaccines, virus-like particles, nano vaccine etc. (Dhama et al., 2008, Dhama et al., 2013c; Delany et al., 2014; Finco \& Rappuoli, 2014; Kim et al., 2014; Singh et al., 2014c; Pany et al., 2015; Singh et al., 2015b). Along with this, for designing, developing and producing effective vaccines the usage of modern adjuvants (TLRs), immunomodulators, and delivery systems is the need of the hour for providing better protection to animals after vaccination (Reed et al., 2013; Dhama et al., 2015b; Singh et al., 2015b). 
Flaring up of several emerging and re-emerging diseases due to several predisposing factors including immune pressures, evolution and mutations in microbes, global warming and rising drug resistance in microbes also demands research attention for exploiting alternative and promising therapeutic options of probiotics, cytokines, si-RNA, egg yolk antibodies (IgY), phages, toll-like receptors, nanomedicines, herbs and nutritional immunomodulators (Blecher et al., 2011; Dhama et al., 2013d; Dhama et al., 2013e; Dhama et al., 2014a; Dhama et al., 2015b; Mahima et al., 2012; Malik et al., 2013c; Tiwari et al., 2013; Tiwari et al., 2014).

Inspite of huge coordinated efforts for the eradication and control of animal diseases like CBPP, RP, and FMD, until now in India rinderpest is the only disease successfully eradicated (Sekar et al., 2011; Bayry, 2013; Balamurugan et al., 2014). India was declared provisionally free from Contagious Bovine Pleuropneumonia (CBBP) from October 2003, however from May 2007, OIE declared India free from CBPP infection
(Singh \& Rana, 2014). Similar attempts are required to control and eradicate the enzootic diseases present in India, which causes more economic losses every year. The disease control programmes in India includes National Control Programme on Brucellosis (NCPB), Foot-and-Mouth Disease Control Programme (FMDCP), avian influenza, preparedness, control and containment, and National Control Programme of Peste des Petits Ruminants (NCPPPR) could not be progressed up to satisfactory level further. In the 12th five year plan, the focus is also given for monitoring and control of certain economically important animal diseases (Sekar et al., 2011). There should be strict implementation on controlled movements/ transport of animals from one state to another as well as strict quarantine measures should be adopted. As being a tropical status of the country, more emphasis should be given on the research and development work for Thermo-durable vaccines so that the dependency over cold chain may be avoided and effective vaccination programme can be implemented (Singh et al., 2009b; Verma et al., 2014b; Sharma et al., 2015).

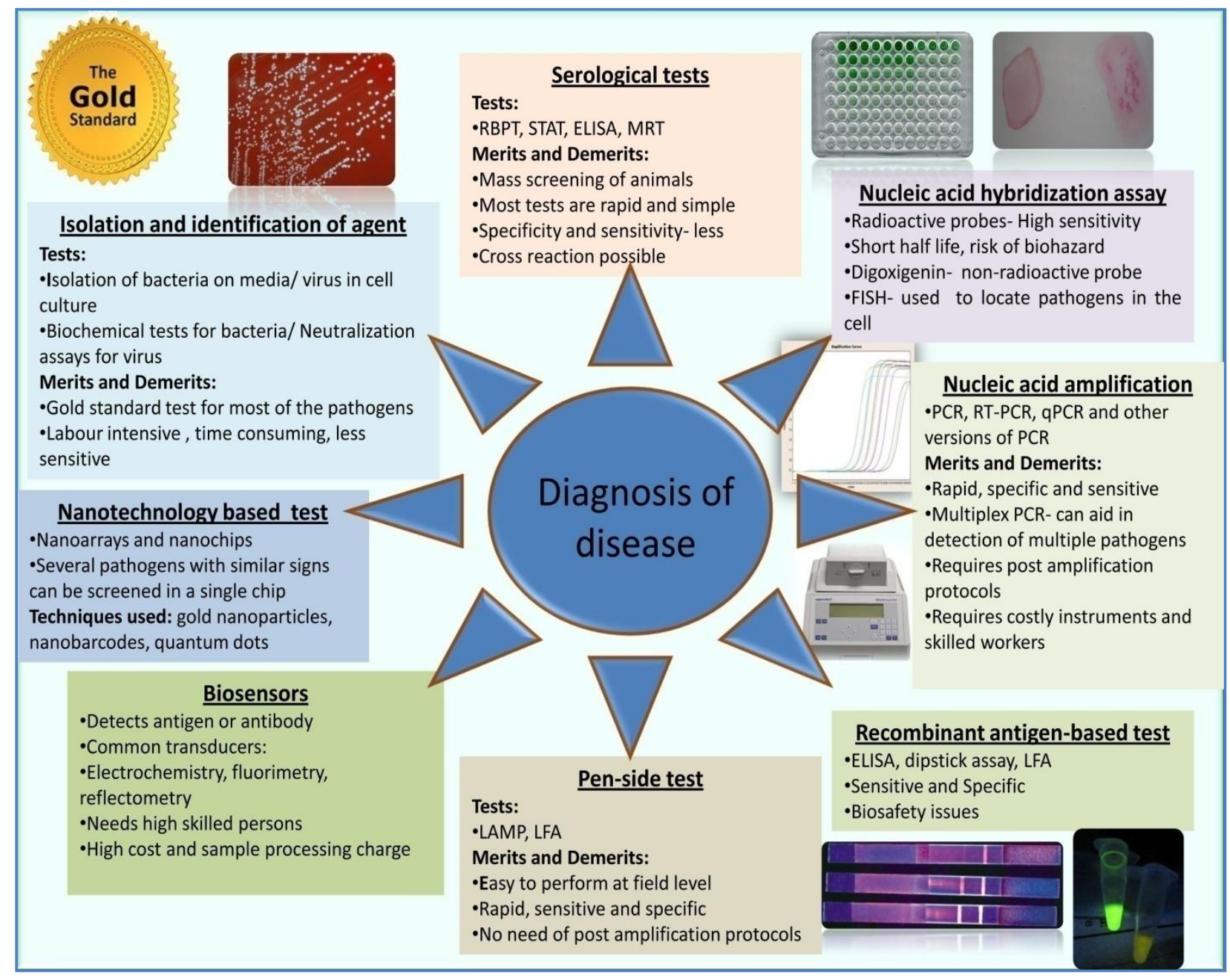

Figure 2 Diagnostic techniques used for diagnosis of different diseases, their merits and demerits. 
8.1 Mass vaccination is a key for disease control

Mass vaccination has been the practical approach for control and eradication of several infectious diseases worldwide. In humans, for the control and eradication of polio, mass vaccination approach was followed by World Health Organization (WHO). Few successful examples are smallpox and polio in humans and rinderpest and CBPP in cattle. Effective control measures along with proper vaccination will get rid of the epidemics of livestock diseases (Sekar et al., 2011). Vaccines will safeguard the livestock by decreasing the spread of infectious agents. Recent molecular advancements like reverse vaccinology resulted in the development of subunit DNA, recombinant and non-pathogenic virus-vectored vaccines leads to production of economically feasible low cost vaccines that are used at field level. In rural areas, basic infrastructure facilities like cold storage needs to be established in veterinary dispensaries to offer improved livestock health services (Bhanuprakash et al., 2010; Bhanuprakash et al., 2011; Dhama et al., 2014a). More work needs to be done in the area of cheaper vaccine development, so as to attract more and more livestock owners to get their animals vaccinated.

\subsection{OIE pathway}

Due to social, ethical and political reasons, restriction of animal movement and test and slaughter policy are difficult to follow in India. Mass vaccination strategy is the feasible, best viable and economical method for control and eradication of diseases (Verma et al., 2014b). India has successfully eradicated the rinderpest by adopting the OIE pathway and in future for successful eradication of any enzootic diseases and to announce the country free from diseases, it is necessary to follow the OIE pathway. OIE pathway includes initial mass immunization, followed by serological surveillance for two years and then no vaccination. These approaches definitely push the country towards free from enzootic diseases results in the declaration of provisional absence of disease. To attain total disease eradication status in the nation a request/report needs to be submitted to the OIE to officially announce as free from disease, after 3 years of the initial declaration. Two consequent yearly serological screening are necessary during this 2 year period. Therefore, a total of 8 to 10 years is needed for officially to declare any disease free from a particular country (Singh et al., 2009b; Verma et al., 2014b; Sharma et al., 2015). It is essential to keep the disease database and disease registry to confirm efficient reporting and monitoring of disease outbreaks. The trained technical, scientific, supporting manpower is required to run a successful disease control program. Surveillance is an effective tool to undertake the disease control program along with mass vaccination. Effective disease forecasting models and programmes need to be developed which have applied applications. These sound models may generate a high confidence level among stakeholders. Further, this may incline them more towards adopting animal husbandry practices to earn their livelihood (Sekar et al., 2011). Veterinarians and para-veterinarians are required to be trained and equipped for rapid diagnosis of disease and reporting actions at the district level. The clinicians and diagnostic laboratory personals have to collect the samples from various places frequently like animal fares, veterinary hospitals, slaughterhouses and livestock farmers who are the direct stakeholders (Singh et al., 2009b; Verma et al., 2014b; Sharma et al., 2015).

\subsection{Cost analysis of control program}

India is still developing the country, analysis of cost for control program is essential. For the implementation of control and eradication program for any diseases needs a considerable amount of financial support from the Government of India. Any disease control programme needs fund for vaccines production and/or purchase, manpower (scientific, technical and supporting), diagnostics, equipment, contingent expenses and infrastructure. In some circumstances, manpower can be arranged by state veterinary departments, research institutes, and colleges. Further to reduce the cost infrastructure facilities developed during the execution of the National Project on Rinderpest Eradication (NPRE) could be used for any disease control and eradication programs after required up gradation (Singh et al., 2009b; Verma et al., 2014b; Sharma et al., 2015).

\subsection{Public-private partnership (PPP)}

A lot of successful stories are available regarding publicprivate partnership in India like ongoing polio control and eradication program. Various non-governmental organizations (NGOs) are significantly contributing to animal husbandry development programmes all over the India. Veterinary vaccines and other biological products are produced by government organizations belonging to both state and central in India. In India, there are 29 biological (vaccines) production centres, among which 22 are under the control and aid of government and 7 are under the control and aid of private sector. Further, many cooperatives are actively contributing for vaccinations, deworming, housing and sheep/goat breeding in many states. The involvement of cooperatives and NGOs are necessary to run the control and eradication programs of diseases. The livestock population is more in India, a large volume of vaccines is needed to implement the programme and hence it is essential to have an association with private manufacturers. Moreover, various NGOs and top private vaccine manufacturers voluntarily undertake the low-cost vaccine production technologies, for launching the control and eradication program (Singh et al., 2009b; Verma et al., 2014b; Sharma et al., 2015).

\subsection{Social and Political Concerns}

Another most important success-determining factor is the political support for disease eradication programmes. To involve the political support, the selected disease for eradication should be need based, economical, international relevance, zoonotic priority and technically feasible. Therefore, clear goal and commitment at various levels are necessary especially in the field staff should be created awareness 
regarding goals and modalities and should be motivated with incentives. The important social requirement for disease eradication programmes from livestock farmers is perseverance. Presently, both social and political importance of many diseases have been understood and could more be taken advantage to support the disease eradication programme at an international level (Singh et al., 2009b; Sharma et al., 2015; Verma et al., 2014b).

\subsection{Constraints in eradication of disease}

Initially, the incidence of the disease in animals is reported by the village livestock farmers or sarpanch of the village or local village assistant to field veterinarians. At that time, the disease is diagnosed on the basis of clinical signs described by the livestock farmers and majority of infected animal dies by the time veterinarian reaches to the village due to insufficient transport facilities. Due to this limitation, a collection of samples from infected animals and subsequent confirmation of the disease would not be possible. Further, many outbreaks of the disease are not reported frequently, hidden and affected animals were sold at low cost. The areas where a veterinarian can arrive the animal before removal, they are unable to collect the samples because of lack of facilities for collection, preservation and transportation to the adjacent laboratory for diagnosis (Chakraborty et al., 2014; Dhama et al., 2014a). A major problem in the control and eradication of diseases using test and slaughter policy is inadequate compensation to the owner for the culling of infected animals. This encourages the owners to hide the clinical sign of the disease in affected areas results in the existence of the disease and animals will act as carriers (Verma et al., 2014c).

8.7 Disinfection of the infected animal premises and their products

Materials and by-products from infected animals like meat and meat products, offal, wool, skin, and hide should be thoroughly disinfected by chemical inactivation, heat treatment, and ionizing irradiation. Milk and dairy products from infected/suspected animals need to be disposed off. Bedding materials from infected animals, feed stuff, excretory and secretary products including dung and urine, and clothing of person working in infected animal houses should be destroyed properly (Chakraborty et al., 2014; Chand et al., 2015).

\subsection{India's Potential to control and eradicate the diseases}

India is a developing country, with 29 states and 7 union territories. The veterinary infrastructure facilities for control and eradication of diseases were available at both central and state levels. A total of 8732 veterinary hospitals (polyclinics), 18,830 veterinary dispensaries and 25,195 veterinary aid centers/stockhome centers/mobile dispensaries were available in the country (Bhanuprakash et al., 2011; http://dahd.nic.in/.). In addition, India has 53 veterinary colleges, and 13 veterinary and animal science universities distributed throughout the country. Further, more than 31 non-governmental organizations (NGOs), 642 Krishi Vigyan Kendras (KVKs) and 23 state biological units were available in the country. Veterinary and animal science has the supreme apex body called as Indian Council of Agricultural Research (ICAR) under which 9 national institutes in the country like, Indian Veterinary Research Institute (IVRI) and National Dairy Research Institute (NDRI), etc., 2 Project Directorates, 6 National Research Centres and one National Bureau of Animal Genetic Resources are there. ICAR is the central organization to plan, implement and execute the control programs with the help of department of animal husbandry under the ministry of agriculture and animal husbandry. The main referral laboratory for disease diagnosis is Centre for Animal Disease Research and Diagnostic (CADRAD), which connects the regional disease diagnostic laboratories (RDDLs) located throughout the country at four zones namely south, north, east and west (Bhanuprakash et al., 2011). With the support of these facilities, India has the potential to control and eradication of diseases in future like rinderpest. India has been declared provisionally free from CBBP from October 2003 and OIE have declared freedom status of India from CBPP infection from May 2007 onwards. Likewise, other animal diseases like foot-and-mouth disease, PPR, Bluetongue, HS, brucellosis, etc., are possible to control and eradication in the future (Bhanuprakash et al., 2011; Verma et al., 2014b).

\section{Conclusion and Future Perspectives}

The animal diseases present in India require a serious attention and needs improved research facilities especially in the field of epidemiology and huge funding. Valid, state-wise, comprehensive research data especially in the field of epidemiology are necessary for planning and control of diseases that are endemic in India, otherwise implementation of control measures will be difficult and eradication will be impossible. Animal diseases are not only danger to the Indian economy but also equally important in reaspect to the human health. During the recent years, majority of the infectious emerging diseases affecting the human are originated from animals. Thus, it is logical to say safeguarding the animal health is most important for maintenance of human health. For successful control of diseases, epidemiological forecasting, quick and correct diagnosis, safer and quality vaccines, sanitation measures along with adequate infrastructure facilities for cold storage and transport facilities to reach the vaccines for the remote areas, where end users are living; are necessary. Advanced diagnostic assays have reduced the puzzle in the diagnosis and differentiation of diseases from others. Door delivery of veterinary services and better extension services for greater awareness to farmers will significantly enhance the possibility of eradication of diseases thus helping in control programmes. The major constraints in the control of disease in the developing country like India are poor vaccination coverage, lack of financial support and insufficient infrastructure, which interferes the building of herd immunity. An interdisciplinary approach like veterinarians, scientist (animal health), medicos, para-veterinary officers, and 
NGOs need to take a leadership role while implementing the control programmes for controlling and eradication of important diseases of livestock. This will increase the livestock production and their sustainability, which ultimately results in alleviation of poverty in the rural areas of the country.

\section{Conflict of interest}

Authors would hereby like to declare that there is no conflict of interests that could possibly arise.

\section{Acknowledgments}

All the authors acknowledge the support from ICAR-Indian Veterinary Research Institute, Izatnagar.

\section{References}

Adinarayanan N, Jain NC, Chandiramani NK, Hajela SK (1960) Studies on leptospirosis among bovines in India. Indian Veterinary Journal 37: 251-254.

Afshar A (1994) Bluetongue: laboratory diagnosis. Comparative Immunology, Microbiology and Infectious Diseases 17: 221-242.

Afshar A, Thomas FC, Wright PF, Shapiro JL, Anderson J (1989) Comparison of competitive ELISA, indirect ELISA and standard AGID tests for detecting bluetongue virus antibodies in cattle and sheep. Veterinary Record 124: 136-141.

Agarwal RA, Singh DK (1988) Harmful gastropods and their control. Acta Hydrochimica Hydrobiologica 16: 113-138.

Agarwal DK, Singh NP (1993) Prevalence of rotavirus infection in cattle in Tarai region. Indian Journal of Animal Science 63: 518-519.

Ambily R, Mini M, Joseph S, Krishna SV, Abhinay G (2013) Canine leptospirosis - a seroprevalence study from Kerala, India. Veterinary World 6: 42-44.

Ananda KJ, D’Souza PE, Puttalakshmamma GC (2009) Prevalence of Haemoprotozoan diseases in crossbred cattle in Bangalore north. Veterinary World 2: 15-16.

Arun TR, Rana R, Singh P, Choudhuri P, Singh VP, Thomas P, Rekha V, Nehra K, Usharani J, Dhama K (2014) Development of a gold nanoparticle based lateral flow assay for rapid diagnosis of contagious agalactia in goats. Asian Journal of Animal and Veterinary Advances 9: 405-413.

Arya SN, Bhatia DK (1992) Incidence of some livestock diseases in Tamil Nadu. Indian Journal of Animal Research 26: 41-43.

Aski HS, Tabatabaei M (2016) Occurrence of Virulenceassociated Genes in Pasteurella multocida Isolates Obtained from Different Hosts. Microbial Pathogenesis pii: S08824010(15)30093-0.

Awase M, Gangwar LS, Patil AK, Goyal G, Omprakash (2013) Assessment of economic losses due to Peste des Petits Ruminants (PPR) disease in goats in Indore Division of Madhya Pradesh. Livestock Research International 1: 61-63.

Balamurugan V, Saravanan P, Sen A, Rajak KK, Venkatesan G, Krishnamoorthy P, Bhanuprakash V, Singh RK (2012) Prevalence of peste des petits ruminants among sheep and goats in India. Journal of Veterinary Science 13: 279-285.

Balamurugan V, Hemadri D, Gajendragad MR, Singh RK, Rahman H (2014) Diagnosis and control of peste des petits ruminants: a comprehensive review. Virus Disease 25: 39-56.

Bandyopadhyay S, Chakraborty D, Sarkar T, Pal B, Sasmal D, Biswas TK, Ghosh MK, Sarkar M (2009a). A serological survey of antibodies against bovine herpesvirus-1 in yak (Poephagus grunniens) in Arunachal Pradesh in India. Revue Scientifique et Technique 28: 1045-50.

Bandyopadhyay S, Sasmal D, Dutta TK, Ghosh MK, Sarkar M, Sasmal NK, Bhattacharya M (2009b) Seroprevalence of brucellosis in yaks (Poephagus grunniens) in India and evaluation of protective immunity to S19 vaccine. Tropical Animal Health Production 41: 587-592.

Banerjee D, Kumar V, Maity A, Ghosh B, Tyagi K, Singha D, Kundu S, Laskar BA, Naskar A, Rath S. (2015) Identification through DNA barcoding of Tabanidae (Diptera) vectors of surra disease in India. ACTA Tropica 150: 52-8. doi: 10.1016/j.actatropica.2015.06.023.

Baqir M, Bhusan S, Sharma D, Kumar A, Saminathan M, Dhama K, Sonwane AA, Kumar P, Chauhan A, Bhaladhare A, Raveendran R, Yadav R, Prakash O (2014) Bovine IL12RB1, IL12RB2, and IL23R polymorphisms and bovine tuberculosis (bTB) infection status. Journal of Pure and Applied Microbiology 8: 4117-4124.

Barbuddhe SB, Malik SVS, Kumar A, Kalorey DR, Chakraborty T (2012) Epidemiology and risk management of listeriosis in India. International Journal of Food Microbiology 154: 113-118.

Barenfus M, Delliquadri CA, Mcintyre RW, Schroeder RJ (1963) Isolation of infectious bovine rhinotracheitis virus from calves with meningoencephalitis. Journal of the American Veterinary Medical Association 143: 725-728.

Bayry J (2013) Emerging viral diseases of livestock in the developing world. Indian Journal of Virology 24: 291-4.

Begum SS, Mahato G, Sharma P, Sharma K, Hussain M, Das BC, Hussain J, De A, Choudhary D, Ramakrishn MA, Muthuchelvan D (2016) Seroprevalence of Peste Des Petits 
Ruminants in Goats in Assam, India. Asian Journal of Animal and Veterinary Advances 11: 210-212.

Behera SP, Mishra N, Vilcek S, Rajukumar K, Nema RK, Prakash A, Kalaiyarasu S, Dubey SC (2011) Genetic and antigenic characterization of bovine viral diarrhoea virus type 2 isolated from cattle in India. Comparative Immunology, Microbiology and Infectious Diseases 34: 189-196.

Benkirane A, De Alwis MCL (2002) Haemorrhagic septicaemia, its significance, prevention and control in Asia. Veterinarni Medicina 47: 234-240.

Bhanot V, Balamurugan V, Bhanuprakash V, Venkatesan G, Sen A, Yadav V, Yogisharadhya R, Singh RK (2009). Expression of P32 protein of goatpox virus in Pichia pastoris and its potential use as a diagnostic antigen in ELISA. Journal Virological Methods 162: 251-257.

Bhanuprakash V, Indrani BK, Hosamani M, Singh RK (2006) The current status of sheeppox disease. Comparative Immunology, Microbiology and Infectious Diseases 29: 27-60.

Bhanuprakash V, Venkatesan G, Balamurugan V, Hosamani M, Yogisharadhya R, Chauhan RS, Pande A, Mondal B, Singh RK (2010) Pox outbreaks in sheep and goats at Makhdoom (Uttar Pradesh), India: evidence of sheeppox virus infection in goats. Transboundary and Emerging Diseases 57: 375-382.

Bhanuprakash V, Hosamani M, Singh RK (2011) Prospects of control and eradication of capripox from the Indian subcontinent: a perspective. Antiviral Research 91: 225-32.

Bhown AS, Habeeb AFSA (1977) Structural studies on epsilon prototoxin of Clostridium perfringens type D. Localization of the site of tryptic scission necessary for activation to epsilontoxin. Biochemical and Biophysical Research Communications 78: 889-896.

Biswal JK, Sanyal A, Rodriguez LL, Subramaniam S, Arzt J, Sharma GK, Hammond JM, Parida S, Mohapatra JK, Mathapati BS, Dash BB, Ranjan R, Rout M, Venketaramanan R, Misri J, Krishna L, Prasad G, Pathak KML, Pattnaik B (2012) Foot-and-mouth disease: Global status and Indian perspective. Indian Journal of Animal Sciences 82: 2012.

Blecher K, Nasir A, Friedman A (2011) The growing role of nanotechnology in combating infectious disease. Virulence 2: 395-401.

Broderson BW (2014) Bovine Viral Diarrhea Virus Infections. Manifestations of Infection and Recent Advances in Understanding Pathogenesis and Control. Veterinary Pathology 51: 453-464.

Brugere-Picoux J (2008) Ovine listeriosis. Small Ruminant Research 76: 12-20.
Chakraborty S, Kumar A, Tiwari R, Rahal A, Malik Y, Dhama K, Pal A, Prasad M (2014) Advances in diagnosis of respiratory diseases of small ruminants. Veterinary Medicine International 2014: 508304.

Chand K, Biswas SK, Pandey AB, Muthuchelvan D, Mondal B (2015) Bluetongue in India: A review. Advances in Animal and Veterinary Sciences 3: 605-612.

Chandran D, Naidu SS, Sugumar P, Rani GS, Vijayan SP, Mathur D, Garg LC, Srinivasan VA (2010) Development of a Recombinant Epsilon Toxoid Vaccine against Enterotoxemia and Its Use as a Combination vaccine with live attenuated sheep pox virus against enterotoxemia and sheep pox. Clinical and Vaccine Immunology 17: 1013-1016.

Chatterjee A, De BN, Mondal P, Bidyanata J, Chakaraborty MK, Nandy AK, Sen GP (1986) Studies on seroprevalence of bovine brucellosis in rural West Bengal. Indian Veterinary Journal 63: 95-100.

Chauhan HC, Biswas SK, Chand K, Rehman W, Das B, Dadawala AI, Chandel BS, Kher HN, Mondal B (2014) Isolation of bluetongue virus serotype 1 from aborted goat fetuses. Scientific and Technical Review of the Office International des Epizooties 33: 803-812.

Chelsea G, Himsworth C, Argue K (2008) Anthrax in Saskatchewan 2006: An outbreak overview. Canadian Veterinary Journal 49: 235-237.

Corchia A, Limelette A, Hubault B, Robbins A, Quinquenel A, Bani-Sadr F, N'Guyen Y (2015) Rapidly evolving conjunctivitis due to Pasteurella multocida, occurring after direct inoculation with animal droplets in an immunocompromised host. BMC ophthalmology 15: 21. doi: 10.1186/s12886-015-0002-6

Davies DG, Harvey RWS (1972) Anthrax infection in bone meal from various countries of origin. The Journal of Hygiene 70: $455-457$.

De Noordhout CM, Devleesschauwer B, Angulo FJ, Verbeke G, Haagsma J, Kirk M, Havelaar A, Speybroeck N (2014) The global burden of listeriosis: a systematic review and metaanalysis. The Lancet Infectious Diseases 14: 1073-1082.

Delany I, Rappuoli R, De Gregorio E (2014) Vaccines for the 21st century. EMBO Molecular Medicine 6: 708-720.

Depa PM, Dimri U, Sharma MC, Tiwari R (2012) Update on epidemiology and control of Foot and Mouth Disease - A menace to international trade and global animal enterprise. Veterinary World 5: 694-704.

Journal of Experimental Biology and Agricultural Sciences

http://www.jebas.org 
Desquesnes M, Holzmuller P, Lai DH, Dargantes A, Lun ZR, Jittaplapong S (2013) Trypanosoma evansi and surra: a review and perspectives on origin, history, distribution, taxonomy, morphology, hosts, and pathogenic effects. Biomed Research International 2013: 194176. doi: 10.1155/2013/194176.

Devendra C (1995) In Global Agenda for Livestock research, EDS, ILRI, Nairobi., pp: 41-48.

Dhama K, Mahendran M, Gupta PK, Rai A (2008) DNA vaccines and their applications in veterinary practice: current perspectives. Veterinary Research Communications 32: 34156.

Dhama K, Wani MY, Tiwari R, Kumar D (2012) Molecular diagnosis of animal diseases: the current trends and perspectives. Livestock Sphere, May issue, pp: 6-10.

Dhama K, Verma AK, Rajagunalan S, Kumar A, Tiwari R, Chakraborty S, Kumar R (2013a) Listeria monocytogenes infection in poultry and its public health importance with special reference to food borne zoonoses. Pakistan Journal of Biological Sciences 16: 301-308.

Dhama K, Verma AK, Tiwari R, Chakraborty S, Vora K, Kapoor S, Deb R, Karthik K, Singh R, Munir M, Natesan S (2013b) A perspective on applications of geographical information system (GIS); an advanced tracking tool for disease surveillance and monitoring in veterinary epidemiology. Advances in Animal and Veterinary Sciences 1: $14-24$.

Dhama K, Wani MY, Deb R, Karthik K, Tiwari R, Barathidasan R, Kumar A, Mahima, Verma AK, Singh SD (2013c) Plant based oral vaccines for human and animal pathogens - a new era of prophylaxis: Current and future perspectives. Journal of Experimental Biology and Agricultural Sciences 1: 1-12.

Dhama K, Tiwari R, Chakraborty S, Kumar A, Karikalan M, Singh R, Rai RB (2013d) Global warming and emerging infectious diseases of animals and humans: current scenario, challenges, solutions and future perspectives - a review. International Journal of Current Research 5: 1942-1958.

Dhama K, Chakraborty S, Mahima, Wani MY, Verma AK, Deb R, Tiwari R, Kapoor S (2013e) Novel and emerging therapies safeguarding health of humans and their companion animals: a review. Pakistan Journal of Biological Sciences 16: $1-11$.

Dhama K, Chakraborty S, Tiwari R, Verma AK, Saminathan M, Amarpal, Malik YS, Nikousefat Z, Javdani M, Khan RU (2014a) A concept paper on novel technologies boosting production and safeguarding health of humans and animals. Research Opinions in Animal and Veterinary Sciences 4: 353 370.
Dhama K, Karthik K, Chakraborty S, Tiwari R, Kapoor S, Kumar A, Thomas P (2014b) Loop-mediated isothermal amplification of DNA (LAMP) - a new diagnostic tool lights the world of diagnosis of Animal and Human Pathogens: A review. Pakistan Journal of Biological Sciences 17: 151-166.

Dhama K, Karthik K, Tiwari R, Shabbir MZ, Barbuddhe S, Malik SV, Singh RK (2015a) Listeriosis in animals, its public health significance (food-borne zoonosis) and advances in diagnosis and control: A comprehensive review. Veterinary Quarterly 35: 211-35.

Dhama K, Saminathan M, Jacob SS, Singh M, Karthik K, Amarpal, Tiwari R, Sunkara LT, Malik YS, Singh RK (2015b) Effect of immunomodulation and immunomodulatory agents on health with some bioactive principles, modes of action and potent biomedical applications. International Journal of Pharmacology 11: 253-290.

Dhar P, Sreenivasa BP, Barrett T, Corteyn M, Singh RP, Bandyopadhyay SK (2002) Recent epidemiology of peste des petits ruminants virus (PPRV). Veterinary Microbiology 88 : 153-159.

Drevets DA, Bronze MS (2008) Listeria monocytogenes: epidemiology, human disease, and mechanisms of brain invasion. FEMS Immunology and Medical Microbiology 53: 151-165.

Dutta J, Rathore BS, Mullick SG, Singh R, Sharma GC (1990) Epidemiological studies on occurrence of Hamemorrhagic Septicaemia in India. Indian Veterinary Journal 67: 893-899.

Elbers ARW, Backx A, Mintiens K, Gerbier G, Staubach C, Hendrickx G, van der Spek A (2008) Field observations during the bluetongue serotype 8 epidemic in 2006. II. Morbidity and mortality rates, case fatality and clinical recovery in sheep and cattle in the Netherlands. Preventive Veterinary Medicine 87:b31-40.

FAO, OIE (2012) Global conference on Foot and Mouth Disease Control, Bangkok, Thailand, 27-29 June, 2012; Recommendations.

Fasanella A, Scasciamacchia S, Garofolo G, Giangaspero A, Tarsitano E, Adone R (2010) Evaluation of the house fly Musca domestica as a mechanical vector for an anthrax. PLoS One 5: e12219.

Finco O, Rappuoli R (2014) Designing vaccines for the twenty-first century society. Frontiers in Immunology 5:12-17.

Gajendragad MR, Uma S (2012) Haemorrhagic Septicaemia in India. Project Directorate on Animal Disease Monitoring and Surveillance, Bengaluru, Karnataka available on http://www.nadres.res.in access on 25 March, 2016. 
Garg R, Yadav CL, Kumar RR, Banerjee PS, Vatsya S, Godara $R$ (2009) The epidemiology of fasciolosis in ruminants in different geo-climatic regions of north India. Tropical Animal Health Prodution 41: 1695-700.

Garg R, Patil PK, Singh SV, Sharma S, Gandham RK, Singh AV, Filia G, Singh PK, Jayaraman S, Gupta S, Chaubey KK, Tiwari R, Saminathan M, Dhama K, Sohal JS (2015) Comparative Evaluation of Different Test Combinations for Diagnosis of Mycobacterium avium Subspecies paratuberculosis Infecting Dairy Herds in India. BioMed Research International 2015: 983978.

Garner MG, Sawarkar SD, Brett EK, Edwards JR, Kulkarni VB, Boyle DB, Singh SN (2000) The extent and impact of sheep pox and goat pox in the state of Maharashtra, India. Tropical Animal Health Production 32: 205-223.

George N, Bhandari V, Reddy DP, Sharma P (2015) Molecular and Phylogenetic analysis revealed new genotypes of Theileria annulata parasites from India. Parasites and Vectors 8: 468.

Ghosh S, KoBaYaShi N, NaGaShiMa S, NaiK TN (2009) Molecular characterization of full-length genomic segment 2 of a bovine picobirnavirus (PBV) strain: evidence for high genetic diversity with genogroup I PBVs. Journal of General Virology 90: 2519-2524.

Gibbs EPJ (1981) Persistent viral infection of food animals. Their relevance to the international movement of livestock and germplasm. Advances in Veterinary Science and Comparative Medicine, 25: 71-75.

Gill JPS, Kaur S, Joshi DV, Sharma JK (2000) Epidemiological studies on brucellosis in farm animals in Punjab state of India and its public health significance. Proceedings of the 9th International Symposium on Veterinary Epidemiology and Economics, available at www.sciquest.org.nz access on 20th March, 2016.

Goswami TK, Singh DK, Saminathan M, Verma AK, Dhama K (2014) An emerging threat of Crimean Congo hemorrhagic fever: call for preparedness. Advances in Animal and Veterinary Sciences 2: $8-14$.

Grange JM (2001) Mycobacterium bovis infection in human beings. Tuberculosis 81: 71-77.

Greenstein RJ (2003) Is Crohn's disease caused by a Mycobacterium? Comparison with leprosy, tuberculosis, and Johne's disease. The Lancet Infectious Diseases 3: 507-514.

Gulati BR, Maherchandani S, Pandey R (1995) Electropherotyping of genomic RNA of rotavirus from Diarrhoeic calves. Indian Journal of Virology 11: 7-12.

Gunaseelan L, Rishikesavan R, Adarsh T, Baskar R, Hamilton E, Kaneene JB (2011) Temporal and geographical distribution of animal anthrax in Tamil nadu state, India. Tamilnadu Journal of Veterinary and Animal Sciences 7: 277-284.

Gupta RP, Yadav CL, Ruprah NS (1986) The epidemiology of bovine fascioliasis ( $F$. gigantica) in Haryana state. Indian Veterinary Journal 63: 187-190.

Hansa A, Rai RB, Dhama K, Wani MY, Saminathan M, Ranganath GJ (2013) Isolation of bovine coronavirus (BCoV) in Vero cell line and its confirmation by direct FAT and RTPCR. Pakistan Journal of Biological Sciences 16: 1342-1347.

Harkirat S, Jyoti, Haque M, Singh NK, Rath SS (2013) PCR based detection of subclinical bovine babesiosis in Punjab. Indian Journal of Animal Research 47: 543-546.

Hemadri D, Hiremath J (2011) Vision 2030. Project Directorate on Animal Disease Monitoring and Surveillance. Pp. 1-30.

Hernandez-Milian A, Payeras-Cifre A (2014) What Is New in Listeriosis? BioMed Research International 2014: 358051.

Hessman BE, Sjeklocha DB, Fulton RW, Ridpath JF, Johnson BJ, McElroy DR (2012) Acute bovine viral diarrhea associated with extensive mucosal lesions, high morbidity, and mortality in a commercial feedlot. Journal of Veterinary Diagnostic Investigations 24: 397- 404.

Himani D, Suman MK, Mane BG (2013) Epidemiology of leptospirosis: an Indian perspective. Journal of Foodborne and Zoonotic Diseases 1: 6-13.

Huck RA, Millar PG, Evans DH, Stables JW, Ross A (1971) Penoposthitis associated with infectious bovine rhinotracheitisinfectious pustular vulvovaginitis (I.B.R-I.P.V.) virus in a stud of bulls. Veterinary Record 88: 292-297.

Jaiswal AK, Vikrant S, Neha, Verma AK (2015) Insight into Trypanosomiasis in Animals: Various Approaches for its Diagnosis, Treatment and Control: A Review. Asian Journal of Animal Sciences 9: 172-186.

Janakiraman V (2008) Listeriosis in pregnancy: diagnosis, treatment, and prevention. Reviews in Obstetrics and Gynecology 1: 179-185.

Jindal SR, Maiti NK, Oberoi MS (2000) Genomic diversity and prevalence of rotavirus in cow and buffalo calves in northern India. Revue Scientifique et Technique19: 871-876.

Joshi DV, Parkash O (1971) Prevalence of brucellosis in man and animals. Indian Journal of Pathology and Microbiology 14: $96-101$

Joshi DV, Sharma DR, Dhillon SS (1975) Brucellosis on organized farms of Punjab. Tropical Animal Health and Production 13: 8-10. 
Karthik K, Rathore R, Thomas P, Viswas KN, Agarwal RK, Rekha V, Jagapur RV, Dhama K (2016) Rapid and visual loop mediated isothermal amplifi cation (LAMP) test for the detection of Brucella spp. and its applicability in epidemiology of bovine brucellosis. Veterinarski Arhiv 86: 35-47.

Kawadkar J, Chauhan MK, Maharana M (2011) Nanobiotechnology: Application of nanotechnology in diagnosis, drug discovery and drug development. Asian Journal of Pharmaceutical and Clinical Research 4: 23-28.

Khurana B, Pandey P (2001) Evidence of bovine non-group A rotavirus in diarrhoeic neonatal calves in India. Veterinary Record 149: 364-365.

Kim M, Park JY, Shon Y, Kim G, Shim G, Oh Y (2014) Nanotechnology and vaccine development. Asian Journal of Pharmaceutical Sciences 9: 227-235

Kitching RP, Mellor PS (1986) Insect transmission of Capripoxvirus. Research in Veterinary Science 31: 255-258.

Kohli S, Atheya UK, Srivastava SK, Banerjee PS, Garg R (2014) Outbreak of theileriosis and anaplasmosis in herd of Holstein crossbred cows of Dehradun district of Uttranchal, India: A Himalyan region. International Journal of Livestock Production 5: 182-185.

Krishnamoorthy P, Patil SS, Shome R, Rahman H (2015) Seroepidemiology of infectious bovine rhinotracheitis and brucellosis in organised dairy farms in southern India. Indian Journal of Animal Sciences 85: 695-700.

Kulshreshtha RC, Kaira DS, Kapur MR (1978) A study on brucellosis and role of vets in controlling it. Indian Journal of Public Health 22: 332-336.

Kumar P, Singh VK, Singh DK (2009) Kinetics of enzyme inhibition by active molluscicidal agents ferulic acid, umbelliferone, eugenol and limonene in the nervous tissue of snail Lymnaea acuminate. Phytotherapy Research 23: 172 177.

Kumar A, Yogisharadhya R, Ramakrishnan MA, Viswas KN, Shivachandra SB (2013) Structural analysis and crossprotective efficacy of recombinant $87 \mathrm{kDa}$ outer membrane protein (Omp87) of Pasteurella multocida serogroup B:2. Microbial Pathogenesis 65: 48-56.

Kumar VN, Sreenivasulu D, Reddy YN (2014) Prevalence of clostridium perfringens toxin genotypes in enterotoxemia suspected sheep flocks of Andhra Pradesh. Veterinary World 7: 1132-1136.

Kumar R, Singh SP, Savalia CV (2015a) Overview of Emerging Zoonoses in India: Areas of Concern. Journal of Tropical Diseases 3: 165.
Kumar V, Kaur P, Wadhawan VM, Pal H, Sharma H, Kumar P (2015b) Theileriosis in cattle: prevalence and seasonal incidence in Jalandhar district of Punjab (India). International Journal of Recent Scientific Research 6: 2998-2999.

Limmahakhun S, Chayakulkeeree M (2013) Listeria monocytogenes brain abscess: two cases and review of the literature. Southeast Asian Journal of Tropical Medicine and Public Health 44: 468-478.

Maan S, Maan NS, Nomikou K, Veronesi E, Bankowska BK, Manjunatha N, Attoui H, Mertens PPC (2011) Complete Genome characterization of a novel 26th Bluetongue virus serotype from Kuwait. PLoS One 6: e26147.

Maan N, Maan S, Nomikou K, Guimera M, Pullinger G, Singh KP, Belaganahalli MN, Mertens PP (2012) The genome sequence of bluetongue virus type 2 from India: evidence for reassortment between eastern and western topotype field strains. Journal of Virology 86: 5967-5968.

Madhu BP, Singh KP, Saminathan M, Singh R, Tiwari AK, Manjunatha V, Harish C, Manjunathareddy GB (2016) Correlation of inducible nitric oxide synthase (iNOS) inhibition with TNF- $\alpha$, caspase-1, FasL and TLR-3 in pathogenesis of rabies in mouse model. Virus Genes 52: 6170.

Magona JW, Walubengo J, Olaho-Mukani W, Jonsson NN, Welburn SW, Eisler MC (2011) Spatial variation of tick abundance and seroconversion rates of indigenous cattle to Anaplasma marginale, Babesia bigemina and Therileria parva infections in Uganda. Experimental and Applied Acarology 55: 203-213.

Maheshwari G (2012) Current Status of Bluetongue Disease, Its Vector and Pathogenesis in India. Proceedings of the National Academy of Sciences, India Section B: Biological Sciences 82: 463-475.

Mahima, Rahal A, Deb R, Latheef SK, Samad HA, Tiwari R, Verma AK, Kumar A, Dhama K (2012) Immunomodulatory and therapeutic potentials of herbal, traditional/indigenous and ethnoveterinary medicines. Pakistan Journal of Biological Sciences 15: 754-774.

Majumder S, Pandey AB, Ramakrishnan MA (2013a) Seroepidemiology and detection of bovine herpesvirus 1 (BoHV1) antigen in semen of cattle and buffalo by polymerase chain reaction. Indian Journal of Veterinary Pathology 37: 118-120.

Majumder S, Pandey AB, Ramakrishnan MA (2013b) Genetic characterization of complete open reading frame of glycoprotein $\mathrm{C}$ gene of bovine herpesvirus 1 . Veterinary World 6: 897-900. doi: 10.14202/vetworld.2013.897-900 
Majumder S, Pandey AB, Ramakrishnan MA (2014) Cloning and Sequence Analysis of Glycoprotein D Gene of Bovine Herpesvirus. Advances in Animal and Veterinary Sciences 2: 19-22. doi: 10.14737/journal.aavs/2014/2.2s.19.22

Majumder S, Ramakrishnan MA, Nandi S (2015a) Infectious Bovine Rhinotracheitis: An Indian Perspective. International Journal of Current Microbiology and Applied Sciences 4: 844858.

Majumder S, Pandey AB, Ramakrishnan MA (2015b) Sequence and Phylogenetic Analysis of Glycoprotein B Gene of Indian Isolate of Bovine Herpesvirus. International Journal of Current Microbiology and Applied Sciences 4: 789-796.

Malik SV, Barbuddhe SB, Chaudhari SP (2002) Listeric infections in humans and animals in the Indian subcontinent: a review. Tropical Animal Health and Production 34: 359-381.

Malik YPS, Singh D, Chandrashekar KM, Shukla S, Sharma K, Vaid N, Chakravarti S (2011a) Occurrence of Dual Infection of Peste-Des-Petits-Ruminants and Goatpox in Indigenous Goats of Central India. Transboundary and Emerging Diseases 58: 268-273.

Malik YPS, Chandrashekar KM, Sharma, K, Haq AA, Vaid N, Chakarvarti S, Batra M and Pandey AB (2011b). Picobirnavirus detection in bovine and buffalo calves from foothills of Himalaya and central India. Tropical Animal Health Production 43: 1475-8. doi:10.1007/s11250-011-98340 .

Malik YS, Sharma K, Vaid N, Chakravarti S, Chandrashekar KM, Basera SS, Singh R, Minakshi, Prasad G, Gulati BR, Bhilegaonkar KN, Pandey AB (2012) Frequency of group A rotavirus with mixed $G$ and $P$ genotypes in bovines: predominance of G3 genotype and its emergence in combination with G8/G10 types. Journal of Veterinary Science 13: 271-278.

Malik YPS, Kumar N, Sharma AK, Sharma K, Mandal A, Joardar SN, Balasubramanian G (2013a) Molecular evidence of a genetically diverse bubaline picobirnavirus strain, India. Thai Journal of Veterinary Medicine 43: 609-613.

Malik YPS, Kumar N, Sharma K, Haq AA, Kumar A, Prasad M (2013b) Sequence and phylogenetic analysis of bovine rotavirus isolates (G6 genotypes) from India. Advances in Animal and Veterinary Sciences 1: 41-43.

Malik YS, Sharma K, Jeena LM, Kumar N, Sircar S, Rajak KK, Dhama K (2013c) Toll-like receptors: the innate immune receptors with ingenious anti-viral paradigm. South Asian Journal of Experimental Biology 3: 207-213.

Malik YPS, Sharma AK, Kumar N, Sharma K, Balasubramanian G, Kobayashi N (2014) Identification and characterization of a novel genogroup II picobirnavirus in a calf in India. Veterinary Record 174: 278. doi:10.1136/vr.102065.

Malone JB, Gommes R, Hansen J, Yielma JM, Slingenberg J, Snijders F, Nachtergaela F, Ataman E (1998) A geographic information system on potential distribution and abundance of Fasciola hepatica and Fasciola gigantica in east Africa based on Food and Agriculture Organization databases. Veterinary Parasitology 78: 87-101.

Mathew L and Menon, GD (2008) Economic impact of FMD in Chazhoor Panchayath district veterinary centre, Thrissur, Kerala state. Veterinary World 1: 5-6.

Mehrotra ML, Rajya BS, Kumar S (1976) Infectious bovine rhinotracheitis (IBR) keratoconjunctivitis in calves. Indian Journal of Veterinary Pathology 1: 70-73.

Michel AL (2002) Implications of tuberculosis in African wildlife and livestock. Annals of the New York Academy of Sciences 969: 251-255.

Minakshi, Prasad G, Grover YP (2009) Occurrence of dual infection of bovine group A rotavirus in diarrhoeic calf in Haryana, India. Indian Journal of Animal Science 79: 12051208.

Minakshi P, Singh R, Ranjan K, Kumar P, Joshi CG, Reddy YK, Prasad G (2012) Complete genome sequence of bluetongue virus serotype 16 of goat origin from India. Journal of Virology 86: 8337-8338.

Mir MR, Chishti MZ, Rashid M, Dar SA, Katoch R, Mehraj M, Dar MA, Rasool R (2013) The Epidemiology of Caprine Fascioliasis In Jammu (J\&K) - India. International Journal of Food, Agriculture and Veterinary Sciences 3: 233-237.

Mishra N, Pattnaik B, Vilcek S, Patil SS, Jain P, Swamy N, Bhatia S, Pradhan HK (2004) Genetic typing of bovine viral diarrhea virus isolates from India. Veterinary Microbiology 104: 207-212.

Mishra N, Dubey R, Rajukumar K, Tosh C, Tiwari A, Pitale SS, Pradhan HK (2007) Genetic and antigenic characterization of Indian bovine viral diarrhea virus type 2 isolated from Indian goats (Capra hircus). Veterinary Microbiology 124: 340-347.

Mishra N, Rajukumar K, Vilcek S, Tiwari A, Satav JS, Dubey SC (2008) Molecular characterization of bovine viral diarrhea virus type 2 isolate originating from a native Indian sheep (Ovis aries). Veterinary Microbiology 130: 88-98.

Mishra N, Rajukumar K, Tiwari A, Nema RK, Behera SP, Satav JS, Dubey SC (2009) Prevalence of Bovine viral diarrhoea virus (BVDV) antibodies among sheep and goats in India. Tropical Animal Health and Production 4: 1231-1239. 
Mishra N, Rajkumar K, Kalairasu S, Dubey PC (2011) Pestevirus infection, an emerging threat to ruminants in India: A review. Indian Journal of Animal Sciences 80: 545-551.

Mittal SK, Srivastava RN, Prasad S (1991) Epizootiology of rotavirus infection in calves. Indian Journal of Animal Science 61: 353-356.

Mohan A, Das P, Kushwaha N, Karthik K, Niranjan AK (2013) Investigation on the status of Johne's disease based on agar gel immunodiffusion, ziehl-neelsen staining and nested PCR approach in two cattle farm. Veterinary World 6: 778784.

Momotani E, Whipple E, Thiemann A, Gheville N (1988) Role of M Cell and macrophages in the entrance of Mycobacterum paratuberculosis into domes of ileal Peyer's patches in calves. Veterinary Pathology 25: 131-137.

Mukherjee F, Singh BK, Tongaonkar SS, Ramakant, Srivastava PK (1989) Adaptation of bovine viral diarrhoea virus in Aubern University bovine embryonic kidney and vero cell lines, and testing of bovine sera for neutralizing antibodies. Indian Journal of Animal Sciences 59: 631-635.

Muthuchelvan D, De A, Debnath B, Choudhary D, Venkatesan G, Rajak KK, Sudhakar SB, Himadri D, Pandey AB, Parida S ( 2014) Molecular characterization of peste-des-petits ruminants virus (PPRV) isolated from an outbreak in the IndoBangladesh border of Tripura state of North-East India. Veterinary Microbiology 174: 591-595. doi:10.1016/j.vetmic.2014.10.027

Muthuchelvan D, Rajak KK, Ramakrishnan MA, Choudhary D, Bhadouriya S, Saravanan P, Pandey AB, Singh RK (2015) Peste-des-petits-ruminants: An Indian perspective. Advances in Animal Veterinary Sciences 3: 422-429.

Muylkens B, Thiry J, Kirten P, Schynts F, Thiry E (2007) Bovine herpesvirus 1 infection and infectious bovine rhinotracheitis. Veterinary Research 38: 181-209. doi:10.1051/vetres:2006059

Naik G, Ananda KJ, Kavitha Rani B (2010) Theileriosis in calves and its successful treatment. Veterinary World 3: 191.

Nandi S, Kumar M, Manohar M, Chauhan RS (2009) Bovine herpes virus infections in cattle. Animal Health Research Reviews 10: 85-98. doi:10.1017/S1466252309990028.

Nayak BC, Panda SN, Misra DB, Kar BC, Das BC (1982) Note on serological evidence of viral abortion in cattle in Orissa. Indian Journal of Animal Sciences 52: 102-103.

Neeraja D, Veeregowda BM, Rani MS, Rathnamma D, Bhaskaran R, Gowda L, Somshekhar SH, Saminathan M, Dhama K, Chakraborty S (2014a) Comparison of Single Intradermal Test, Gamma Interferon Assay and Indirect ELISA for the Diagnosis of Tuberculosis in a Dairy Farm. Asian Journal of Animal and Veterinary Advances 9: 593-598.

Neeraja D, Veeregowda BM, Rani MS, Rathnamma D, Narayanaswamy HD, Venkatesha MD, Leena G, Apsana R, Somshekhar SH, Saminathan M, Dhama K, Chakraborty S (2014b) Identification of Mycobacterium tuberculosis complex by Culture and Duplex Polymerase Chain Reaction in Bovines. Asian Journal of Animal and Veterinary Advances 9: 506-512.

Neibergs JS, Zanella R, Casas E, Snowder GD, Wenz J, Neibergs JS, Moore D (2011) Loci on Bos taurus chromosome 2 and Bos taurus chromosome 26 are linked with bovine respiratory disease and associated with persistent infection of bovine viral diarrhea virus. Journal of Animal Sciences 89: 907-915.

Nelson DD, Duprau JL, Wolff PL, Evermann JF (2015) Persistent Bovine Viral Diarrhea Virus Infection in Domestic and Wild Small Ruminants and Camelids Including the Mountain Goat (Oreamnos americanus). Frontiers in Microbiology 6: 1415. doi:10.3389/fmicb.2015.01415

Palaniappan RU, Chang YF, Jusuf SS, Artiushin S, Timoney JF, McDonough SP, Barr SC, Divers TJ, Simpson KW, McDonough PL, Mohammed HO (2002) Cloning and molecular characterization of an immunogenic LigA protein of Leptospira interrogans. Infection and Immunity 70: 59245930.

Pandey V, Nigam R, Jaiswal AK, Sudan V, Singh RK, Yadav PK (2015) Haemato-biochemical and oxidative status of buffaloes naturally infected with Trypanosoma evansi. Veterinary Parasitology 212: 118-122.

Pany SS, Mohanty NN, Sarangi LN, Mohapatra JK, Shivachandra SB (2015) Vaccination: a future perspective. Advances in Animal and Veterinary Sciences 3: 1-8.

Pathak KB, Biswas SK, Tembhurne PA, Hosamani M, Bhanuprakash V, Prasad G, Singh RK, Rasool TJ, Mondal B (2008) Prokaryotic expression of truncated VP7 of Bluetongue virus (BTV) and reactivity of the purified recombinant protein with all BTV type-specific sera. Journal of Virological Methods 152: 6-12.

Patil RR (2010) Anthrax: Public Health Risk in India and Socio-Environmental Determinants. Indian Journal of Community Medicine 35: 189-190.

Patil D, Dahake R, Roy S, Mukherjee S, Chowdhary A, Deshmukh R (2014) Prevalence of leptospirosis among dogs and rodents and their possible role in human leptospirosis from Mumbai, India. Indian Journal of Medical Microbiology 32: 64-67. 
Pattnaik B, Subramaniam S, Sanyal A, Mohapatra JK, Dash BB, Ranjan R, Rout M (2012) Foot-and-mouth Disease: Global Status and Future Road Map for Control and Prevention in India. Agricultural Research 1: 132-147.

Prasad HK, Singhal A, Mishra A, Shah NP, Katoch VM, Thakral SS, Singh DV, Chumber S, Bal S, Aggarwal S, Padma MV, Kumar S, Singh MK, Acharya SK (2005) Bovine tuberculosis in India: potential basis for zoonosis. Tuberculosis 85: 421-428.

Prasad KL, Kondaiah PM, Rayulu VC, Srilatha CH (2015) Prevalence of canine trypanosomiasis in certain areas of Andhra Pradesh. Journal of Parasitic Diseases 39: 238-40. doi: 10.1007/s12639-013-0326-1.

Pringle CR (1999) Virus Taxonomy: The universal system of virus taxonomy updated to include new proposals ratified by international committee on Taxonomy of viruses during 1998. Archives of Virology 144: 422-429.

Promed.org (2011) available on http://www.promedmail.org/direct.php?id=2011 0925.2912. Accessed on 10th April, 2013.

Radostits OM, Gay CC, Hinchcliff KW, Constable PD (2007) Veterinary Medicine. Text book of the diseases of cattle, sheep, pig and goats, 10th Edn. Saunders Elsevier publication, Philadelphia, USA. pp: 1537-1538.

Rahman H, Bhattacwarya M, Rajkhowa, J, Soud, N, Nandankar U, Mukherjee S (2007) Seroprevalenee of infectious bovine rhinstracheitis in yaks (Poephagus grunniens) in India. Indian Journal of Animal Sciences 77: 793-795.

Rajeev R, Panda SK, Acharya AP, Singh AP, Gupta MK (2011) Molecular diagnosis of Haemorrhagic Septicaemia - A Review. Veterinary World 4: 189-192. doi:10.5455/vetworld.2011.189-192

Rajkhowa S, Rajkhowa C, Rahman H, Bujarbaruah KM (2004) Seroprevalence of infectious bovine rhinotracheitis in mithun (Bos frontalis) in India. Revue Scientifique et Technique 23: 821-829.

Ramakrishnan MA, Pandey AB, Singh KP, Singh R, Mehrotra ML (2005a) Immune response and protective efficacy in sheep immunised with hydroxylamine-inactivated bluetongue virus vaccine. Veterinaria Italiana 41: 149-155.

Ramakrishnan MA, Singh KP, Pandey AB, Singh R, Nandi S, Mehrotra ML (2005b) Genomic diversity of Indian isolates of bluetongue virus. Acta Virologica 49: 285-286.

Ramakrishnan MA, Pandey AB, Singh KP, Singh R, Nandi S, Mehrotra ML (2006) Immune responses and protective efficacy of binary ethylenimine (BEI)-inactivated bluetongue virus vaccines in sheep. Veterinary Research Communications 30: 873-880. doi:10.1007/s11259-006-3313-5

Rana R, Srivastava NC, Singh VP (1999) Monitoring of humoral response in goats immunized with killed Mycoplasma mycoides subsp. capri saponin vaccine by slide agglutinatioin and latex agglutination tests. Indian Journal of Comparative Microbiology Immunology and Infectious Diseases 20: 39-41

Rani NL, Suresh, K, Rajesh, K (2015) A retrospective study on clinico-epidemiological aspects of trypanosomiasis in buffaloes. International Journal of Veterinary Science 4: 97100 .

Rao PP, Reddy YV, Meena K, Karunasree N, Susmitha B, Uma M, Prasad PUVS, Chaitanya P, Reddy YN, Hegde NR (2012) Genetic characterization of bluetongue virus serotype 9 isolates from India. Virus Genes 44: 1-9.

Rao PP, Hegde NR, Reddy YN, Krishnajyothi Y, Reddy YV, Susmitha B, Gollapalli SR, Putty K, Reddy GH (2016) Epidemiology of Bluetongue in India. Transboundary and Emerging Diseases 63: e151-164. doi:10.1111/tbed.12258.

Ravindran R, Mishra AK, Rao JR (2002) On the high seroprevalence of bovine babesiosis in Wayanad district of Kerala. Journal of Applied Animal Research 22: 43-48.

Rebagliati V, Philippi R, Rossi M, Troncoso A (2009) Prevention of foodborne listeriosis. Indian Journal of Pathology and Microbiology 52: 145-149.

Reddy YKM, Manohar BM, Pandey AB, Reddy YN, Prasad G, Chauhan RS (2010) Development and evaluation of inactivated pentavalent adjuvanted vaccine for Bluetongue. Indian Veterinary Journal 87: 434-436.

Reed SG, Orr MT, Fox CB (2013) Key roles of adjuvants in modern vaccines. Nature Medicine 19: 1597-1608.

Rekha V, Rana R, Arun TR, Awasthi PB, John JK, Gopinath D, Sadanandan GV, Jacob A (2014) Loop mediated Isothermal Amplification (LAMP) test - a novel nucleic acid based assay for the disease diagnosis. Advances in Animal and Veterinary Sciences 2: 344-350

Rekha V, Rana R, Thomas P, Konasagara Nagaleekar Viswas, Singh VP, Agarwal RK, Arun TR, Karthik K Sophia I (2015) Development of loop-mediated isothermal amplification test for the diagnosis of contagious agalactia in goats. Tropical Animal Health and Production 47: 581-587.

Renukaradhya GJ, Rajasekhar M, Raghavan R (1996) Prevalence of infectious bovine rhinotracheitis in southern India. Scientific and Technical Review OIE 15: 1021-1028. 
Renukardhya GJ, Isloor S, Rajasekhar M (2002) Epidemiology, zoonotic aspects, vaccination and control/eradication of brucellosis in India. Veterinary Microbiology 90: 183-195.

Rood JI, Cole ST (1991) Molecular genetics and pathogenesis of Clostridium perfringes. Microbiological Reviews 55: 621648.

Roy S, Tiwari A, Galdhar CN, Upadhyay SR, Ratre HK, Sahu SK, Maiti SK (2004) Seasonal prevalence of haemoprotozoan diseases in cross- bred cattle and buffaloes. Indian Journal of Veterinary Medicine 24: 5-7.

Rweyemamu M, Roeder P, Mackay D, Sumption K, Brownlie J, Leforban Y, Valarcher JF, Knowles NJ, Saraiva V (2008) Epidemiological patterns of Foot-and-Mouth disease worldwide. Transboundary and Emerging Diseases 55: 57-72. doi:10.1111/j.1865-1682.2007.01013.x

Sambasiva RR, Naveen G, Bhalla P, Agarwal SK (2003) Leptospirosis in India and the rest of the world. Brazilian Journal of Infectious Diseases 7: 178-193.

Saminathan M, Karuppanasamy K, Pavulraj S, Gopalakrishnan A, Rai RB (2013) Acute Encephalitis Syndrome - A Complex Zoonotic Disease. International Journal of Livestock Research 3: 174-177.

Sandhu GK (2011) Tuberculosis: Current situation, challenges and overview of its control programs in India. Journal of Global Infectious Diseases 3: 143-50.

Santhamani R, Yogisharadhya R, Venkatesan G, Shivachandra SB, Pandey AB, Ramakrishnan MA (2013) Detection and differentiation of sheeppox virus and goatpox virus from clinical samples using $30 \mathrm{kDa}$ RNA polymerase subunit (RPO30) gene based PCR. Veterinary World 6: 923-925.

Santhamani R, Venkatesan G, Minhas SK, Shivachandra SB, Muthuchelvan D, Pandey AB, Ramakrishnan MA (2015) Detection and characterization of atypical Capripoxviruses among small ruminants in India. Virus Genes 51: 33-38.

Santhamani R, Yogisharadhya R, Venkatesan G, Shivachandra SB, Pandey AB, Ramakrishnan MA (2014) Molecular characterization of Indian sheeppox and goatpox viruses based on RPO30 and GPCR genes. Virus Genes 49: 286-291. doi:10.1007/s11262-014-1095-3

Sapre SN (1964) An outbreak of bluetongue in goats and sheep in Maharastra state. Indian Veterinary Review M \& B 15: 6971.

Sarangi LN, Thomas P, Gupta SK, Kumar S, Viswas KN, Singh VP (2016) Molecular Epidemiology of Pasteurella multocida Circulating in India by Multilocus Sequence Typing.
Transboundary and Emerging Diseases 63: e286-92. doi: 10.1111/tbed.12270.

Saravanan BC, Das S, Siju SJ, Tewari AK, Sankar M, Kataktalware MA, Ramesha KP (2013) Babesia bigemina infection in yak (Poephagus grunniens L.): molecular detection and characterization. Veterinary Parasitology 194: 58-64.

Sarmah S, Mahato G, Sharma K, Sharma P, George S (2015) Seroprevalence of Infectious Bovine Rhinotracheitis in Breeding Bulls of Assam. IOSR Journal of Agriculture and Veterinary Science 8: 14-15.

Sekar N, Shah NK, Abbas SS, Kakkar M (2011) Research Options for Controlling Zoonotic Disease in India, 2010-2015. PLoS One 6: e17120.

Selvaraj J, Murali Manohar B, Balachandran C, Kiran Kumar KK, Gajendran MR (2008) Current status of seroprevalence of infectious bovine rhinotracheitis using avidin-biotin ELISA in she-buffaloes. Tamil Nadu Journal of Veterinary and Animal Sciences 4: 33-34.

Sen A, Saravanan P, Balamurugan V, Rajak KK, Sudhakar SB, Bhanuprakash V, Parida S, Singh RK (2010) Vaccines against peste des petits ruminants virus. Expert Review of Vaccines 9: 785-796.

Sevilla I, Singh SV, Juste RA, Kumar V, Bhatia AK (2004) Paratuberculosis bison genotype strain isolated from sheep and goat. Journal of Immunology and Immunopathology 6: 137.

Sevilla I, Singh SV, Garrido JM, Aduriz G, Rodr1'guez S, Geijo MV, Whittington RJ, Saunders V, Whitlock RH, Juste RA (2005) PCR-REA genotype paratuberculosis strains isolated from different host and species and geographic locations. Scientific and Technical Review of the Office International des Epizooties 24: 1061-6.

Shah NM, Jhala MK (1992) Epizootiological Investigations on rotavirus infection in cases of neonatal calf diarrhoea. Indian Veterinary Journal 69: 5-7.

Shaila MS, Purashothaman V, Bhavsar D, Venugopal K, Venkatesan RA (1989) Peste des petits ruminants of sheep in India. Veterinary Record 125: 602.

Sharma RL, Dhar DN, Raina OK (1989) Studies on the prevalence and laboratory transmission of fascioliasis in animals in the Kashmir Valley. The British Veterinary Journal 145: $57-61$

Sharma A, Das Singla L, Tuli A, Kaur P, Batth BK, Javed M, Juyal PD (2013) Molecular prevalence of Babesia bigemina and Trypanosoma evansi in dairy animals from Punjab, India, by duplex PCR: a step forward to the detection and 
management of concurrent latent infections. Biomed Research International 2013: 893862.

Sharma GK, Mahajan S, Matura R, Subramaniam S, Ranjan R, Biswal J, Rout M, Mohapatra JK, Dash BB, Sanyal A, Pattnaik B (2015) Diagnostic assays developed for the control of footand-mouth disease in India. World Journal of Virology 4: 295302 .

Sheikh GN, Qadri GJ, Gunjan D (2007) Seasonal prevalence of bovine fascioliasis in Kashmir valley. Indian Journal of Veterinary Medicine 27: 119-120.

Shivachandra SB, Viswas KN, Kumar AAA (2011) Review of hemorrhagic septicemia in cattle and buffalo. Animal Health Research Reviews 12: 67-82.

Shivachandra SB, Kumar A, Yogisharadhya R, Ramakrishnan MA, Viswas KN (2013) Carboxyl terminus heterogeneity of type IV fimbrial subunit protein of Pasteurella multocida isolates. Veterinary Research Communications 37: 269-275.

Shivachandra SB, Kumar A, Mohanty NN, Yogisharadhya R, Chacko N, Viswas KN, Ramakrishnan MA (2014a) Homogeneity of VacJ outer membrane lipoproteins among Pasteurella multocida strains and heterogeneity among members of Pasteurellaceae. Research in Veterinary Science 96: 415-421.

Shivachandra SB, Kumar A, Yogisharadhya R, Viswas KN (2014b) Immunogenicity of highly conserved recombinant VacJ outer membrane lipoprotein of Pasteurella multocida. Vaccine 32: 290-296. doi:10.1016/j.vaccine.2013.10.075

Shivachandra SB, Yogisharadhya R, Kumar A, Mohanty NN, Nagaleekar VK (2015) Recombinant transferrin binding protein A (rTbpA) fragments of Pasteurella multocida serogroup B: 2 provide variable protection following homologous challenge in mouse model. Research in Veterinary Science 98: 1-6.

Shome R, Nagalingam M, Rahman H (2012) National Control Program on Brucellosis: Aims and strategies. Project Directorate on Animal Disease Monitoring and Surveillance, Technical Bulletin /15/2012.

Singh O, Agarwal RA (1981) Toxicity of certain pesticides to two economic species of snail in northern India. Journal of Economic Entomology 74: 568-571.

Singh J, Gill JS, Kwatra MS, Sharma KK (1993) Treatment of theileriosis in crossbred cattle in the Punjab. Tropical Animal Health Production 25: 75-78.

Singh VP, Sinha DK, Gupta SK, Chauhan RS (2008a) Prevalence of HS in India. Vth Annual Scientist Meet on Haemorrhagic Septicaemia at Guwahati, 5-6th Sept, 2008.
Singh SV, Singh AV, Singh R, Sharma S, Shukla N, Misra S, Singh PK, Sohal JS, Kumar H, Patil PK, Misra P, Sandhu KS (2008b) Sero-prevalence of bovine Johne's disease in buffaloes and cattle population of North India using indigenous ELISA kit based on native Mycobacterium avium subspecies paratuberculosis 'Bison type' genotype of goat origin. Comparative Immunology, Microbiology and Infectious Diseases 31: 419-33.

Singh H, Mishra AK, Rao JR, Tewari AK (2009a) Comparison of indirect fluorescent antibody test (IFAT) and slide enzyme linked immunosorbent assay (SELISA) for diagnosis of Babesia bigemina infection in bovines. Tropical Animal Health Production 41: 153-9.

Singh RK, Balamurugan V, Bhanuprakash V, Sen A, Saravanan P, Yadav MP (2009b) Possible control and eradication of peste des petits ruminants from India: technical aspects. Veterinaria Italiana 45: 449-462.

Singh SK, Yadav RP, Singh A (2010) Molluscicides from some common medicinal plants of eastern Uttar Pradesh, India. Journal of Applied Toxicology 30: 1-7. doi: 10.1002/jat.1498.

Singh RP (2011) Control strategies for peste des petits ruminants in small ruminants of India. Scientific and Technical Review of the Office International des Epizooties 30: 879.

Singh AV, Singh SV, Singh PK, Sohal JS, Singh MK (2011) High prevalence of Mycobacterium avium subspecies paratuberculosis (Indian bison type) in animal attendants suffering from gastrointestinal complaints who work with goat herds endemic for Johne's disease in India. International Journal of Infectious Diseases 15: e677-83.

Singh NK, Singh H, Jyoti, Haque M, Rath SS (2012) Prevalence of parasitic infections in cattle of Ludhiana district, Punjab. Journal of Parasitic Diseases 36: 256-259.

Singh D, Sharma K, Kadam M and Malik YPS (2013) Sequence and phylogenetic analysis of a peste-des-petitsruminants (PPR) virus isolated from central India. Indian Journal of Animal Sciences 83: 32-34.

Singh VP, Rana R (2014) Contagious Bovine Pleuropneumonia-infection and its eradication. Indian Farming 64: 15-18.

Singh B, Prasad S, Verma MR, Sinha DK (2014a) Estimation of Economic Losses due to Haemorrhagic Septicaemia in Cattle and Buffaloes in India. Agricultural Economics Research Review 27: 271-279.

Singh SV, Sohal JS, Kumar N, Gupta S, Chaubey KK, Rawat KD, Chakraborty S, Tiwari R, Dhama K (2014b) Recent approaches in diagnosis and control of mycobacterial infections with special reference to Mycobacterium avium 
subspecies paratuberculosis. Advances in Animal and Veterinary Sciences 2: 1-11.

Singh AK, Verma AK, Neha, Tiwari R, Karthik K,. Dhama K, Singh SV (2014c) Trends and advances in vaccines against protozoan parasites of veterinary importance: A review. Journal of Biological Sciences 14: 95-109.

Singh BB, Dhand NK, Gill JPS (2015a) Economic losses occurring due to brucellosis in Indian livestock populations. Preventive Veterinary Medicine 119: 211-215.

Singh RK, Badasara SK, Dhama K, Malik YPS (2015b) Progress and prospects in vaccine research. In: Current Trends and Future Research Challenges in Vaccines and Adjuvants. In: Malik YPS, Sagar P, Dhama K, Singh RK (Eds.). Souvenir, National Workshop Organized at Indian Veterinary Research Institute, Izatnagar 243122, Bareilly, Uttar Pradesh, India during 19-20 November 2015, Pp: 1-19.

Sivajothi S, Rayulu VC, Malakondaiah P, Sreenivasulu D (2013) Colloidal Dye Immunobinding Assay for Detection of Trypanosoma evansi Antibodies in Animals. International Journal of Livestock Research 3: 48-56.

Sivakumar P, Tripathi BN, Singh N (2005) Detection of Mycobacterium avium subsp. paratuberculosis in intestinal and lymph node tissues of water buffaloes (Bubalus bubalis) by PCR and bacterial culture. Veterinary Microbiology 108: 262-270.

Sivaseelan S, Uma Rani R, Kathiresan D (2003) Seroprevalence of Leptospirosis in sheeps and goats on Madurai. Indian Veterinary Journal 80: 375.

Smits HL, Kadri SM (2005) Brucellosis in India: a deceptive infectious disease. Indian Joutrnal of Medical Research 122: 375-384.

Sood R, Bhatia S, Gounalan S, Patil SS, Patnaik B (2007) Seroprevaence of Boviine Viral Diarrhoea Virus in India, A survey. Indian Journal of Animal Sciences 77: 667-671.

Srivastava SK, Verma R, Harbola PC (1991) Seroprevalence of leptospirosis in animals and man in India. Indian Journal of Animal Science 60: 1439-1441.

Srivastava SK (2008) Current status of leptospirosis in India in animals and humans. Indian Journal of Veterinary Pathology 32: $179-186$.

Subramaniam S, Pattnaik B, Sanyal A, Mohapatra JK, Pawar SS, Sharma GK, Das B, Dash BB (2013) Status of foot-andmouth disease in India. Transboundary and Emerging Diseases 60: 197-203. doi: 10.1111/j.1865-1682.2012.01332.x.

Sudharsana KJ, Suresh KB, Rajasekhar M (1999) Prevalence of bovine viral diarrhoea virus antibodies in India. Scientific and Technical Review of the Office International des Epizooties 18: 667-671.

Suresh S, Ramakrishna J, Saeendranath MR, Tresamol PV, Bhat MN (1993) Serosurvey of bovine brucellosis in Tamilnadu, A recent study. Cherion 22: 1-7.

Swarnakar G, Sanger B (2014) Epidemiological study of liver fluke (Trematoda: Digenea) in Domestic Ruminants of Udaipur District. International Journal of Current Microbiology and Applied Sciences 3: 632-640.

Talley P, Snippes-Vagnone P, Smith K (2016) Invasive Pasteurella multocida Infections - Report of Five Cases at a Minnesota Hospital, 2014. Zoonoses and Public Health doi: 10.1111/zph.12263

Taylor WP (1984) The distribution and epidemiology of peste des petits ruminants in the sultanate of oman. Veterinary Microbiology 22: 341-352.

Tewari AK, Saravanan BC, Sudan V, Maharana BR, Sudhakar NR (2013) Trypanosomosis caused by T. evansi: An insight. Livestock Management Product Technology and Health pp: 409411.

Thakur A, Sharma M, Katoch VC, Dhar P, Katoch RC (2010) A study on the prevalence of Bovine Tuberculosis in farmed dairy cattle in Himachal Pradesh. Veterinary World 3: 409414.

Thapa NK, Tenzin, Wangdi K, Dorji T, Migma, Dorjee J, Marston CK, Hoffmaster AR (2014) Investigation and Control of Anthrax Outbreak at the Human-Animal Interface, Bhutan, 2010. Emerging Infectious Disease 20: 1524-1526.

Thombare NN, Sinha MK (2009) Economic Implications of Peste des petits ruminants (PPR) Disease in Sheep and Goats: A Sample Analysis of District Pune, Maharastra. Agricultural Economics Research Review 22: 319-322.

Tiwari R, Chakraborty S, Dhama K, Rajagunalan S, Singh SV (2013) Antibiotic resistance - an emerging health problem: causes, worries, challenges and solutions - a review. International Journal of Current Research 5: 1880-1892.

Tiwari R, Chakraborty S, Dhama K, Wani MY, Kumar A, Kapoor S (2014) Wonder world of phages: potential biocontrol agents safeguarding biosphere and health of animals and humans - current scenario and perspectives. Pakistan Journal of Biological Sciences 17: 316-328.

Tripathi BN (2008) Paratuberculosis (Johne's disease) in animals: Pathogenesis, diagnosis and zoonotic significance. Indian Journal of Veterinary Pathology 32: 187-199.

Uzal FA, Kelly WR, Morris WE, Bermudez J, Baison, M (2004) The pathology of peracute experimental Clostridium 
perfringens type $\mathrm{D}$ enterotoxemia in sheep. Journal of Veterinary Diagnostic Investigation 16: 403-411.

Vahora SP, Patel JV, Parel BB, Patel SB, Umale RH (2012) Seasonal incidence of haemoprotozoan diseases in crossbred cattle and buffalo in Kaira and Anand district of Gujarat, India. Veterinary World 5: 223-225.

Hurk R, Evoy S (2015) A review of membrane-based biosensors for pathogen detection. Sensors, 15: 14045-14078.

Varma A, Rai RB, Balakrishnan P, Gupta A, Naveen KA (2001) Seroprevalence of leptospirosis in animals of Andaman and Nicobar Islands. Indian Veterinary Journal 78: 936.

Venkataramanan R, Hemadri D, Bandyopadhyay SK, Taneja VK (2006) Foot-and mouth Disease in India: Present status. Paper presented at a workshop on Global Roadmap for improving the tools to control foot-and-mouth disease in endemic settings. 29 Nov - 1 Dec 2006, Agra, India.

Vera A, Gonzalez G, Domínguez M, Bello H (2013) Main virulence factors of Listeria monocytogenes and its regulation. Rev Chilena Infectol. 30: 407-416.

Verma AK, Pal BC, Singh CP, Jain U, Yadav SK, Mahima (2008) Studies of the outbreaks of foot-and-mouth disease in Uttar Pradesh, India, between 2000 and 2006. Asian Journal of Epidemiology 1: 40-46.

Verma AK, Mahima, Pal BC, Yadav SK, Kumar A, Raies M (2010) Phylogenetic relationships between foot-and-mouth disease virus serotype 'A' isolates and vaccine strains. Online Journal of Veterinary Research 14: 87-95.

Verma AK, Kumar A, Mahima, Sahzad (2012) Epidemiology and diagnosis of foot-and-mouth disease: A review. Indian Journal of Animal Sciences 82: 543-551.

Verma AK, Tiwari R, Chakraborty S, Neha, Saminathan M, Dhama K, Singh SV (2014a) Insights into Bovine Tuberculosis
(bTB), Various Approaches for its Diagnosis, Control and its Public Health Concerns: An Update. Asian Journal of Animal and Veterinary Advances 9: 323-344.

Verma AK, Dhama K, Chakraborty S, Kumar A, Tiwari R, Rahal A, Mahima, Singh SV (2014b) Strategies for Combating and Eradicating Important Infectious Diseases of Animals with Particular Reference to India: Present and Future Perspectives. Asian Journal of Animal and Veterinary Advances 9: 77-106.

Verma AK, Saminathan M, Neha, Tiwari R, Dhama K, Singh SV (2014c) Glanders-A re-emerging zoonotic disease: a review. Journal of Biological Sciences 14: 38-51.

Wadhwa DR, Pal B, Mandial RK (2008) Epidemiological and clinico-therapeutic study of babesiosis in cattle. Indian Journal of Veterinary Research 17: 22-24.

Waters WR, Maggioli MF, McGill JL, Lyashchenko KP, Palmer MV (2014) Relevance of bovine tuberculosis research to the understanding of human disease: historical perspectives, approaches, and immunologic mechanisms. Veterinary Immunology and Immunopathology 159: 113-132.

Wells SJ, Wagner BA (2000) Herd-level risk factors for infection with Mycobacterium paratuberculosis in US dairies and association between familiarity of the herd manager with the disease of prior diagnosis of the disease and use of preventive measures. Journal of the American Veterinary Medical Association 216: 1450-1457.

Zahid UN, Mathan Kumar S, Randhawa Sarnarinder S, Randhawa Swaran S, Hassan MN (2012) Black Quarter in crossbred dairy cattle- A Case Report. Veterinary World 5: 767-770.

Zientara S, Sailleau C, Viarouge C, Höper D, Beer M, Jenckel M, Hoffmann B, Romey A, Bakkali-Kassimi L, Fablet A, Vitour D, Bréard E (2014) Novel bluetongue virus in goats, Corsica, France. Emerging Infectious Disease 20: 2123-2125. 